\title{
JOGOS ANALÓGICOS E DIGITAIS COMO FERRAMENTAS LÚDICAS NA AMBIENTAÇÃO E NO ENSINO DE ESTUDANTES SURDOS EM SALAS DE AULA REGULARES
}

\author{
ANALOG AND DIGITAL GAMES AS PLAYING TOOLS IN THE ENVIRONMENT \\ AND TEACHING OF DEAF STUDENTS IN REGULAR CLASSROOMS
}

\begin{abstract}
JUEGOS ANALÓGICOS Y DIGITALES COMO HERRAMIENTAS DE JUEGO EN EL ENTORNO Y ENSEÑANZA DE ESTUDIANTES SORDOS EN AULAS REGULARES
\end{abstract}

\author{
David Santana Lopes \\ David Kaique Rodrigues dos Santos
}

\begin{abstract}
Resumo
O processo de escolarização de estudantes surdos no Brasil, segundo autores clássicos na área como Ana Regina e Souza Campello, é resultado de um contexto histórico de luta, em meio a conjunto de obstáculos infraestruturais, formativos e curriculares quanto ao processo de ensino-aprendizagem dos mesmos em salas de aula regulares. Desta forma, tomando como base tais problemáticas e compreendendo a necessidade da elaboração de ferramentas didático-pedagógicas que possam potencializar a prática docente em diferentes espaços formativos, este artigo buscou analisar de que forma os jogos analógicos e digitais podem contribuir tanto para 0 processo de ambientação como no ensino de estudantes surdos. Para isso foi realizada uma revisão sistemática da literatura sobre a articulação entre jogos digitais/analógicos e o ensino de estudantes surdos. Com base na análise realizada, se identificou um maior número de trabalhos vinculados ao uso de jogos analógicos, além da grande associação desses, juntamente com os jogos digitais, com abordagens de cunho medicalizante. Diante deste contexto, foram propostos dois modelos de intervenção e verificado o potencial das ferramentas lúdicas, jogos analógicos e digitais, frente à trajetória formativa de estudantes surdos em meio ao ambiente de ensino, o corpo docente e estudantes ouvintes em questão.
\end{abstract}

\begin{abstract}
The schooling process of deaf students in Brazil, according to classic authors in the field such as Ana Regina and Souza Campello, is the result of a historical context of struggle, in the midst of a set of infrastructure, training and curricular obstacles regarding the teaching-learning process of students. even in regular classrooms. Thus, based on such problems and understanding the need for the development of didacticpedagogical tools that can enhance the teaching practice in different training spaces, this article sought to analyze how analog and digital games can contribute both to the process of setting as in teaching deaf students. For this, a systematic review of the literature was carried out on the articulation between digital / analog games and the teaching of deaf students. Based on the analysis carried out, a greater number of works related to the use of analog games were identified, in addition to their great association, together with digital games, with medicalizing approaches. In this context, two intervention models were proposed and the potential of recreational tools, analog and digital games was verified, given the formative trajectory of deaf students in the teaching environment, the faculty and listening students in question.
\end{abstract}




\section{Resumen}

El proceso de escolarización de los estudiantes sordos en Brasil, según autores clásicos en el campo, como Ana Regina y Souza Campello, es el resultado de un contexto histórico de lucha, en medio de un conjunto de infraestructura, capacitación y obstáculos curriculares con respecto al proceso de enseñanza-aprendizaje de los estudiantes. incluso en aulas regulares. Por lo tanto, basándose en tales problemas y entendiendo la necesidad del desarrollo de herramientas didáctico-pedagógicas que puedan mejorar la práctica docente en diferentes espacios de entrenamiento, este artículo buscó analizar cómo los juegos analógicos y digitales pueden contribuir tanto al proceso de configuración como en la enseñanza de estudiantes sordos. Para ello, se realizó una revisión sistemática de la literatura sobre la articulación entre juegos digitales / analógicos y la enseñanza de estudiantes sordos. Con base en el análisis realizado, se identificó un mayor número de trabajos relacionados con el uso de juegos analógicos, además de su gran asociación, junto con los juegos digitales, con enfoques medicalizantes. En este contexto, se propusieron dos modelos de intervención y se verificó el potencial de las herramientas recreativas, los juegos analógicos y digitales, dada la trayectoria formativa de los estudiantes sordos en el entorno de enseñanza, la facultad y los estudiantes en cuestión.

Palavras-chave: Ensino e Ambientação de Estudantes Surdos; Ferramentas Lúdicas; Jogos Analógicos; Jogos Digitais.

Keywords: Teaching and Setting of Deaf Students; Playful Tools; Analog Games; Digital games.

Palabras claves: Enseñanza y configuración de estudiantes sordos; Herramientas juguetonas; Juegos análogos; Juegos digitales.

\section{PERSPECTIVAS INICIAIS}

O processo de escolarização de estudantes surdos no Brasil é resultado de um contexto histórico de luta (CAMPELLO, 2016) contra uma conjuntura que ainda se constitui sob a égide de preconceitos, desconfianças e patologização (STROBEL, 2008) daquilo que deveria ser considerado como mais um exemplo de diversidade. Contudo, apenas na década de 1990, que a luta pelo reconhecimento da Libras se intensificou e começou a ganhar novos contornos, principalmente com sua inserção aos documentos orientadores da educação nacional, como a Lei de Diretrizes e Bases da Educação Brasileira LDB (BRASIL, 1996).

Entretanto, mesmo com a obrigatoriedade na implementação do processo de escolarização da Educação Especial e Inclusiva na Legislação Federal, inúmeras lacunas nos anos que se sucederam ainda precisaram ser contempladas. Até o momento documentos orientadores, como a Lei 10.436 de 24 de abril de 2002 (seguido do Decreto 5626/2005) ou da Lei de 12.319 de 2010, avançaram nas discussões acerca da garantia do ensino e à formação do(a) Tradutor(a)/Intérprete de Libras, mas ainda apresentam dificuldades de inserção no ambiente escolar em decorrência da complexidade do contexto educacional contemporâneo.

Desta forma é preciso considerar ainda as dificuldades enfrentadas na formação inicial (também continuada) de professores quanto à preparação para uma possível (e ainda discutida) Educação Inclusiva diante do processo de ensino-aprendizagem de estudantes com surdez (VIANA; GOMES, 2017) em escolas regulares. Nesse sentido, a formação de profissionais que saibam lidar 
com as demandas de estudantes surdos no qual o respeito à Cultura Surda e a compreensão do real significado do uso da Libras se tornem os pilares na edificação de uma didática ativa em sala de aula (RODRIGUES; MOURA; TESTA, 2011), que valorize recursos didáticos que incentivem a ambientação, interação e, finalmente, uma inclusão que saiba respeitar as demandas de um(a) estudante surdo(a).

Portanto, tomando como base as questões elencadas e diversas ferramentas didáticopedagógicas que possam potencializar o processo de ensino-aprendizagem, em sala de aula, este artigo objetiva analisar de que forma os jogos analógicos e digitais podem contribuir tanto para o processo de ambientação como no ensino de estudantes surdos. Para isso, foi realizada uma revisão sistemática da literatura (FLICK, 2009), descrevendo e analisando de que forma produções acadêmicas vêm retratando a adoção desses instrumentos pedagógicos em ambientes de ensino regular que possuam a presença de estudantes surdos. Em complemento, serão descritos dois modelos de intervenção passíveis de serem implementados a partir da mediação com os jogos analógicos e digitais.

\section{INTERFACES TEÓRICAS DA PESQUISA}

As reflexões acerca da articulação entre as possibilidades de adoção de jogos analógicos e digitais, juntamente com os processos de ambientação e ensino de estudantes surdos, fomentaram o desenvolvimento do presente estudo. Para isso foi utilizado como aporte teórico quatro referenciais básicos, Huizinga (2000); Rodrigues (2017); Perlin e Strobel (2008) e Silva (2016), pautando-se em três pilares temáticos ligados à importância do jogo como ferramenta de ensino; à prática da inclusão de estudantes surdos na educação regular, além dos pressupostos entre a ludicidade e a educação de surdos.

\section{DIFICULDADES NO ENSINO DE ESTUDANTES SURDOS}

O desenvolvimento desse artigo fundamenta-se na necessidade de construir possíveis ferramentas educacionais que possam potencializar o processo de aprendizagem estudantil (DARSIE, 2015). Uma aprendizagem ${ }^{1}$ voltada, principalmente, aos grupos corriqueiramente marginalizados na sociedade atual perante valores biologizantes e padronizantes ligados à educação (CAMPELLO, 2008), como é o que ocorre com os estudantes surdos.

Em suma, se vivencia na contemporaneidade um período de práticas ou métodos didático-pedagógicos, que se alicerçam em propostas desarticuladas com as demandas do atual mundo digital (LEVY, 2010) e suas consequências, diretas ou indiretas, nas dinâmicas empregadas nos espaços formativos. A escola configura-se, portanto, como um espaço fluido e em constante tensão

\footnotetext{
${ }^{1}$ Neste estudo, compreende-se aprendizagem como um processo mediado, ou seja, segue os princípios básicos de Vygotsky (1988) quanto à posição estratégica do professor no processo de ensino ao prover a mediação necessária, seja através dos mais variados artefatos pedagógicos, sociais, culturais e históricos, para o entendimento consciente por parte do estudante.
} 
entre a própria cultura escolar e as multiplicidades identitárias (CANDAU, 2008) contidas em seus estudantes, professores e gestores.

Inserido nesse contexto de disputas políticas, econômicas, sociais e culturais estão as dificuldades enfrentadas pelos partícipes do espaço escolar para o desenvolvimento de um processo de ensino-aprendizagem significativo e contextualizado. Desde a infraestrutura escolar até a valorização da prática docente, os diferentes profissionais de ensino precisam buscar associações teórico-práticas, cada vez mais elaboradas e inovadoras que valorizem, tanto o interesse como as experiências estudantis, em prol de uma aprendizagem que possibilite aos mesmos ressignificar a própria função da escola (OLIVEIRA; REIS, 2017).

Entretanto, quando é acrescentado ao cerne dessa discussão, fatores que busquem também a valorização dos referidos grupos estudantis marginalizados (SÁ, 2011), as questões vinculadas ao processo de ambientação e ensino desses estudantes ganham outros contornos e novas dificuldades. No entanto, o presente artigo limita sua lente de investigação para as demandas e subjetividades ligadas à Cultura Surda, anexando a esse contexto, tensões quanto ao uso da Libras ou da inclusão de estudantes surdos no ensino regular, geralmente implementado em ambientes sem o devido preparo profissional ou que não possuam ferramentas pedagógicos (PIVETTA; SAITO; ULBRICHT, 2014) que proporcionem uma real e significativa imersão desses estudantes surdos nas salas de aula.

Dentre as ferramentas didáticas passíveis de serem adotadas, as atividades lúdicas, materializadas aqui através dos Jogos Analógicos e Digitais, podem ser caracterizados dentro dos pressupostos de Caillois (2017, p. 17) como um conjunto de artefatos "coerentes e equilibrados, ora de direitos e deveres, ora de privilégios e de responsabilidades [...] que reforça, exacerba alguma manifestação física ou intelectual".

Desta forma, os jogos sejam eles analógicos ou digitais, são objetosculturais (PETRY, 2016) que potencializam entre e em seus usuários a forma como "nos relacionamos, nosso modo de ser [...] a partir de fundamentos conceituais [...] sob o domínio de diversas áreas do conhecimento" (PETRY, 2016, p. 17-18). Desta forma, este estudo credita aos Jogos Analógicos e Digitais ferramentas que possam permitir uma maior interação dos estudantes surdos tanto com os estudantes ouvintes como também com o próprio espaço formativo em questão, já que o sistema de inclusão de estudantes surdos na escola regular no Brasil é falho em sua organização estrutural ou política (QUADROS, 2003) e em sua esfera formativa. Neste sentido, a prática em sala de aula regular carece de ferramentas pedagógicas, disponíveis para o corpo docente, que facilitem o processo de ensino-aprendizagem tanto para os estudantes surdos como para os ouvintes (FIALHO, 2008), contribuindo assim para uma ambientação prévia a um espaço corriqueiramente incômodo e repleto de obstáculos na aprendizagem dos primeiros.

\section{A AMBIENTAÇÃO NOS ESPAÇOS FORMATIVOS: POSSIBILIDADES PARA OS ESTUDANTES SURDOS}

Uma das problemáticas centrais vivenciadas pelo corpo docente na Educação Básica perante o ensino de estudantes surdos se insere aos 
obstáculos enfrentados pelos mesmos em promover, no ambiente da sala de aula variadas abordagens didáticas para um contingente, cada vez maior, de identidades estudantis. Nesse contexto, o ensino de estudantes surdos em ambientes que se desenvolve a educação regular, obrigatoriamente, desvela para o corpo docente demandas práticas e teóricas imprescindíveis para lidar com as subjetividades e a riqueza presente na Cultura Surda.

Desta forma, Quadros (2003, p. 104) já descrevia anos atrás que é necessário evitar a todo custo a "tendência das escolas inclusivas em "homogeneizar" as produções culturais e sociais, pois não há uma política que incorpore todas as implicações surdas [...] não há uma preocupação com a coletividade". Isto é a escola regular e seus sujeitos participantes se preocupam tanto em incluir o estudante surdo a uma realidade, muitas vezes imprópria e inoportuna à sua identidade, que ignoram suas demandas, enxergando apenas sobre uma lente baseada em um padrão discente segregador e injusto.

Contudo, o corpo docente convive diariamente com a incerteza promovida pelo atual sistema educacional brasileiro que busca uma inclusão, mas que deposita nesses mesmos professores a responsabilidade por discernir como construir um planejamento que seja satisfatório tanto para ouvintes como também para os estudantes surdos (SÁ, 2011). Porém, questionamentos despontam desse contexto, como por exemplo, de que forma é possível promover a inclusão e antes disso a ambientação do estudante surdo em um espaço, como já mencionado, muitas vezes segregador e injusto? Diante deste cenário, como é possível promover um processo de ensino-aprendizagem que seja relevante às demandas desses estudantes e da coletividade de subjetividades também presentes em sala de aula?

Muitas são as indagações pertinentes a esse contexto formativo, mas existem alternativas didático-pedagógicas, como a adoção da ludicidade que podem auxiliar na ambientação do estudante surdo juntamente com o restante do corpo discente presente em sala de aula (CAMPELLO, 2008), ou seja, que permita trazer condições de interagir e se familiarizar com esse ambiente, como já mencionado, incômodo. Além disso, as intervenções de caráter lúdico podem conceder diferentes trajetórias teórico-práticas possíveis de potencializar o processo de aprendizagem do estudante surdo, frente a uma maior aproximação, não apenas com a Libras, mas com a própria Cultura Surda.

Entretanto, de que forma ferramentas lúdicas podem contribuir tanto no processo de ambientação como no ensino-aprendizagem de estudantes surdos em salas de aula regulares? Essa, portanto, se caracteriza como o questionamento central deste estudo, pois agrega nele, por um lado, a necessidade do corpo docente em buscar novas ferramentas formativas e, por outro, da incerteza de como criar intervenções pedagógicas que se desenvolvam em torno dessa ludicidade, materializada aqui através dos Jogos Analógicos e Digitais. 


\section{A ADOÇÃO DE JOGOS ANALÓGICOS E DIGITAIS NO PROCESSO DE ENSINO-APRENDIZAGEM}

No que se refere à importância do jogo nos processos formativos, Huizinga (2000), em seu livro Homo Ludens caracteriza as inúmeras possibilidades educacionais, além das sociais e culturais contidas na utilização do jogo, seja ele analógico ou digital, no dia a dia do indivíduo praticante. Segundo Huizinga (2000, p. 5), "o jogo é mais do que um fenômeno fisiológico ou um reflexo psicológico [...] ele transcende as necessidades imediatas da vida e confere um sentido à ação", além de promover interações entre os participantes e laços diante dos desafios presentes no jogo.

Em complemento, o próprio Huizinga (2000) afirma que o jogo, em qualquer de suas formas concretas, oferece aos seus praticantes experiências coletivas e individuais que não se isolam em um único campo linguístico, mas que se abrem para uma linguagem universal: terminar o jogo, seja através de uma vitória ou da derrota. Desta forma, a proposta de adoção de jogos de tabuleiro ou digitais no presente estudo sustenta-se na tentativa de criar uma proposta didática que sirva como sugestão para professores(as) da Educação Básica que necessitem de ferramentas, que não apenas inclua os(as) estudantes surdos(as) na dinâmica em sala, mas que eles possam se sentir como partícipes desse ambiente formativo em questão, estando também em diálogo direto com os estudantes ouvintes para a construção de saberes e opiniões.

Nesse sentido, Perlin e Strobel (2008) afirmam que é preciso estimular, via a experimentação, ludicidade e o aporte digital, outras competências estudantis capazes de abrir caminhos formativos que construam elos significativos para a aprendizagem do grupo padrão (ouvintes) com àqueles normalmente suprimidos na prática de ensino em sala de aula (como os estudantes surdos). Portanto, é imprescindível que seja estimulado o uso de jogos para potencializar 0 desenvolvimento de situações formativas "cooperativas e interacionais, no qual o aluno (surdo) ao participar do jogo estará aprendendo a executar regras [...] ao mesmo tempo, desenvolvendo ações de cooperação e interação que estimulem a convivência em grupo" (SILVA, 2017, p. 50), sua ambiência no espaço e gere contribuições significativas em sua aprendizagem.

\section{TRAJETÓRIA METODOLÓGICA}

Este estudo pode ser caracterizado como uma pesquisa qualitativa de cunho empírico e exploratório (BARBOSA, 2017). Em suma, o percurso metodológico escolhido foi baseado nos pressupostos de Denzin e Lincoln (2006) e Flick (2009), que fundamentam a construção e o desenvolvimento do estudo desde a organização das fontes de pesquisa utilizadas até a aplicação dos procedimentos de produção e análise das informações obtidas durante as etapas metodológicas. Com bases nesses autores foi realizada uma Revisão Sistemática da Literatura (FLICK, 2009), além da adoção dos pressupostos de Behar (2009) para a idealização de modelos ou materiais didáticos pautados no uso de jogos analógicos e digitais durante o ensino de estudantes surdos em salas de aula regulares. 


\section{CARACTERÍSTICAS DA REVISÃO SISTEMÁTICA DA LITERATURA}

De forma geral, uma revisão sistemática caracteriza-se por ser "um tipo de investigação focada em uma questão de pesquisa bem definida, que visa identificar, selecionar, avaliar e sintetizar as evidências relevantes disponíveis, em trabalhos acadêmicos" (GALVÃO; PEREIRA, 2014, p. 183) acerca do objeto de estudo em questão. Com base nessas revisões é possível mapear o espectro de trabalhos na área, permitindo que possam ser apontadas características quanto ao objeto pesquisado em diferentes áreas ou campos do saber.

Desta forma, o presente estudo adotou a revisão sistemática da literatura no intuito de levantar as produções científicas (Teses, Dissertações, Artigos, Trabalhos de Conclusão de Curso ou TCC e Trabalhos Publicados em Anais de Eventos) focadas no uso de jogos de tabuleiro e digitais durante 0 processo de ensino de estudantes surdos. Neste sentido, o corpo de trabalhos acadêmicos analisados foi obtido a partir da base de dados presentes na Plataforma de Periódicos da Capes e no Google Acadêmico, apresentando como descritores os termos: a) Jogos Analógicos (ou Tabuleiro ${ }^{2}$ ) e Surdez ou Deficiência Auditiva ${ }^{3}$; b) Jogos Digitais e Surdez ou Deficiência Auditiva; c) Digital Games and Deafness ou Hearing Impairment; d) BoardGames and Deafness ou Hearing Impairment; e) Juegos Analógicos (o Tablero) y Sordero ou Pérdida de Audición e f) Juegos Digitales y Sordero ou Pérdida de Audición.

O refinamento da busca foi determinado através de artigos científicos e periódicos revisados por pares, ou seja, corrigidos a partir da apreciação de corpo editorial/científico especializado na área, garantindo assim confiabilidade dos trabalhos acadêmicos selecionados.

Em complemento, os critérios de inclusão e exclusão quanto a presença ou não de estudos sobre jogos analógicos e digitais articulados com o ensino, aprendizagem e/ou inclusão de estudantes surdos em espaços voltados à educação regular foram os pressupostos adotados para a sistematização do corpus obtido. Por fim, o período de delimitação da busca por trabalhos (DENZIN; LINCOLN, 2006) foi definido a partir do marco histórico/cultural da Lei o 10.436, de 24 de abril, de 2002, denominada como Lei da Libras, no qual ocorreu a regulamentação da Língua Brasileira de Sinais como um sistema linguístico de natureza visual-motora até o presente momento, o ano de 2019.

\section{PLANEJAMENTO E ELABORAÇÃO DE MODELOS DE INTERVENÇÃO}

A elaboração dos modelos de intervenção parte do conceito estabelecido por Bandeira (2009, p. 14) como "produtos pedagógicos utilizados

\footnotetext{
2 O termo tabuleiro foi utilizado como descritor por ser mais conhecido seja na esfera acadêmica como pessoal do que o termo analógico que passou a existir após o surgimento dos jogos digitais.

${ }^{3}$ A expressão deficiência auditiva e variantes como estudante com necessidades especiais se insere na esfera patológica e biologizante da surdez não sendo indicada sua adoção quando em pauta a própria Cultura Surda, contudo ela será por vezes apresentadas neste estudo, pois ainda são expressões utilizadas em um grande número de produções acadêmicas de diferentes áreas.
} 
na educação e, especificamente, como material instrucional que se elabora com finalidade didática", ou seja, todo e qualquer artefato didático que forneça contribuições nos diferentes aspectos ligados ao processo de ensino, neste caso, articulado com a própria prática docente. Nesse sentido, compreende-se que a proposição de modelos de intervenção no presente artigo, oportunizará que professores e demais profissionais do campo da educação possam espelhar tais estruturas em possíveis adaptações às demandas dos seus respectivos espaços formativos.

Para a construção de tais modelos de intervenção, voltados para um ensino conjunto de estudantes surdos e ouvintes em salas de aula regulares, os pressupostos de Behar (2009) sobre o Design Pedagógico foram adotados como princípios norteadores para a elaboração dos diferentes elementos dos referidos materiais instrucionais.

Em suma, para a construção desses artefatos didáticos, mesmo que as orientações de Behar (2009) sejam inicialmente voltadas para a Educação à Distância (EaD), as etapas definidas pela autora contemplam também as atribuições corriqueiras para o ambiente presencial já que para a própria Behar (2009, p. 27, grifo nosso) "[...] o conteúdo é "o que" será trabalhado [...] este pode ser desde um simples material instrucional, um software educacional, páginas Web ou objetos de aprendizagem, é preciso também levar em conta os fatores técnicos, gráficos e pedagógicos, se é motivador (ou não) para o aluno".

Seguindo tais pressupostos, o presente estudo se utiliza da arquitetura interativa dos jogos analógicos (HUIZINGA, 2000) e digitais (TORRES; ALVES, 2017) para formatar a estrutura gráfica a ser apresentada nas intervenções didáticas quanto aos materiais utilizados. Em complemento, o fator técnico segue a própria dinâmica adotada pelo docente em sala de aula diante da interação entre estudantes surdos, ouvintes e entre si com o objeto didático em questão. Por fim, o fator pedagógico articula-se com o próprio paradigma educacional que substancia a prática do docente. Independentemente do perfil apresentado é imprescindível que o modelo de intervenção relacione o conteúdo com o individual de cada estudante, neste caso, lindando com subjetividades da Cultura Surda (CAMPELLO, 2008).

\section{RESULTADOS E DISCUSSÃO}

\section{SISTEMATIZAÇÃO E ANÁLISE DA REVISÃO SISTEMÁTICA}

A revisão sistemática realizada totalizou um corpus final de 54 trabalhos acadêmicos (Gráfico 1) após o refinamento implementado através dos critérios de inclusão e exclusão. Foram selecionados 6 dissertações (11\%), 3 trabalhos de conclusão de curso (5\%), 36 artigos científicos (67\%) e 9 trabalhos vinculados a anais de evento (17\%). Nesse sentido, ao longo da seleção do corpus não foi identificada nenhuma tese de doutorado que configure como uma produção articulada com o objeto de investigação do presente estudo. Essa situação aponta para a necessidade de pesquisas derivadas que possam se aprofundar, por exemplo, nos repositórios acadêmicos de Instituições de Ensino Superior (IES), focando assim em mais trabalhos vinculados diretamente aos cursos de Pós-Graduações Stricto Sensu. 
Gráfico 1: Distribuição por tipo de trabalho acadêmico

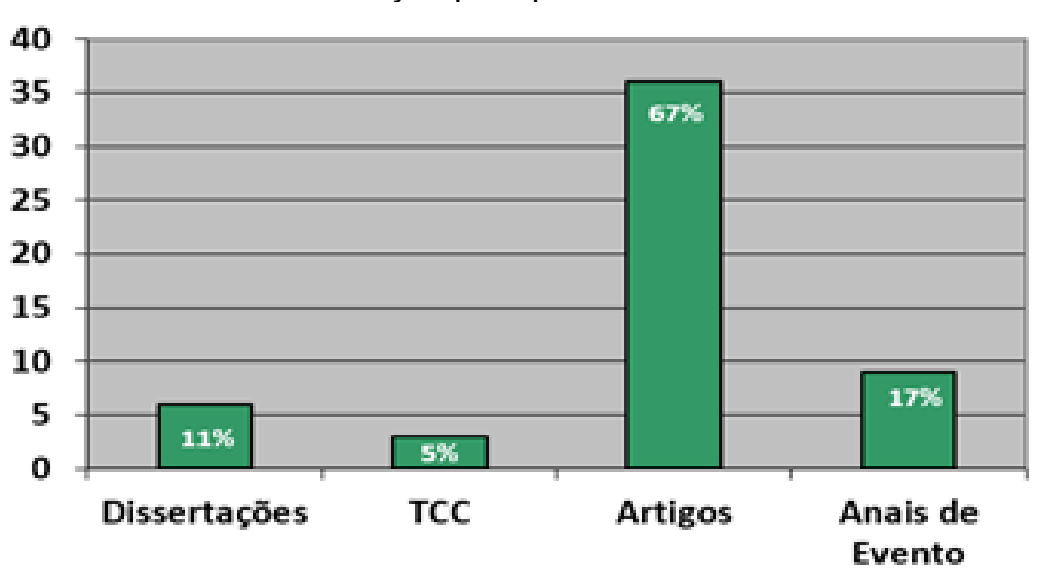

Fonte: Autores

A maioria dos estudos investigados (30 trabalhos) descreveram experiências de ensino-aprendizagem com a presença de estudantes surdos e a adoção de jogos analógicos em diferentes espaços formativos (Quadro 1). Por outro lado, experiências práticas e teóricas relacionadas aos jogos digitais em associação com o ensino de estudantes surdos apresentou um total de 24 trabalhos acadêmicos. Mesmo se tratando de uma diferença pequena, o resultado contraria a tendência contemporânea vinculada ao incentivo cada vez maior de jogos eletrônicos nos ambientes de ensino (TORRES; ALVES, 2015; RIBEIRO et al., 2015; RAMOS; MELO e MATTAR, 2018) sejam como meros instrumentos complementares da prática docente ou como recursos norteadores de planos de aula ou de intervenção.

Quadro 1: Distribuição por descritor de análise

\begin{tabular}{|c|c|c|}
\hline $\begin{array}{c}\text { Descritor } \\
\text { Adotado }\end{array}$ & Autor (Ano) & Total \\
\hline $\begin{array}{c}\text { Jogos Digitais e } \\
\text { Surdez }\end{array}$ & $\begin{array}{c}\text { Artigo: Nascimento e Liz (2017); Rodrigues e Alves (2014) } \\
\text { Anais/Evento: Reichert et al (2015) }\end{array}$ & 6 \\
\hline $\begin{array}{c}\text { Jogos Digitais e } \\
\text { Deficiência } \\
\text { Auditiva }\end{array}$ & Dissertação: Canteri (2014); Cheiran (2013) e Barbosa (2011) & 1 \\
\hline $\begin{array}{c}\text { Digital Games } \\
\text { and Deafness }\end{array}$ & $\begin{array}{c}\text { Artigo: Cano et al. (2018a); Cano et al. (2015); Waki, Fujiyoshi e } \\
\text { Almeida (2015); Bierre et al. (2014); Mascio et al (2013) e Moura et al. } \\
\text { (2013) }\end{array}$ & 6 \\
\hline $\begin{array}{c}\text { Digital Games } \\
\text { and Hearing } \\
\text { Impairment }\end{array}$ & $\begin{array}{c}\text { Artigo: Cano et al. (2018b); Ponsa e Guasch (2018); Schmidt e Marchi } \\
\text { (2017); Cano et al. (2016a); Cano et al. (2016b); Gerling et al. (2012) }\end{array}$ & 6 \\
\hline $\begin{array}{c}\text { Juegos Digitales } \\
\text { y Sordero }\end{array}$ & $\begin{array}{c}\text { Artigo: González-Pena et al. (2017) } \\
\text { TCC: Balceda (2017) }\end{array}$ & 3 \\
\hline $\begin{array}{c}\text { Juegos Digitales } \\
\text { y Pérdida de } \\
\text { Audición }\end{array}$ & Anais/Evento: Cano et al. (2016c) & 2 \\
\hline
\end{tabular}




\begin{tabular}{|c|c|c|}
\hline \multicolumn{2}{|r|}{ Total de Trabalhos Acadêmicos Vinculados aos Jogos Digitais } & 24 \\
\hline $\begin{array}{l}\text { Jogos } \\
\text { Analógicos (ou } \\
\text { Tabuleiro) e } \\
\text { Surdez }\end{array}$ & $\begin{array}{l}\text { Artigo: Oliveira et al. (2019); Dessbesel, Silva e Shimazaki (2018); } \\
\text { Pantoja e Pereira (2018); Caldas (2016); Costa e Silveira (2014); } \\
\text { Bisognin (2013) } \\
\text { Anais/Evento: Oliveira et al. (2018); Queiroz, Canuto e Onofre (2017); } \\
\text { Caldeira, Souza e Ananias (2013); Giordani e Ribas (2013); Dallan } \\
\text { (2009) } \\
\text { Dissertação: Goffi (2009) } \\
\text { TCC: Baqueta (2012) }\end{array}$ & 13 \\
\hline $\begin{array}{l}\text { Jogos } \\
\text { Analógicos (ou } \\
\text { Tabuleiro) e } \\
\text { Deficiência } \\
\text { Auditiva }\end{array}$ & $\begin{array}{l}\text { Artigo: Mariani et al. (2016); Ferreira e Nascimento (2014) } \\
\text { Anais/Eventos: Forte, Dainese e Kirner (2006) }\end{array}$ & 3 \\
\hline $\begin{array}{l}\text { Board Games } \\
\text { and Deafness }\end{array}$ & $\begin{array}{c}\text { Artigo: Guimarães et al. (2017); Vasconcelos et al. (2015); Caporusso, } \\
\text { Mkrtchya e Badia (2009); Gillam (2008); Saliés e Starosky (2008); } \\
\text { Savidis, Grammenos e Stephanidis (2007); Grammenos, Savidis e } \\
\text { Stephanidis (2005) } \\
\text { Anais/Evento: Melonio e Gennari (2013) }\end{array}$ & 8 \\
\hline $\begin{array}{l}\text { Board Games } \\
\text { and Hearing } \\
\text { Impairment }\end{array}$ & Artigo: Yuan; Folmer e Harris (2011); Leung e Lam (2007) & 2 \\
\hline $\begin{array}{l}\text { Juegos } \\
\text { Analógicos (o } \\
\text { Tablero) y } \\
\text { Sordero }\end{array}$ & $\begin{array}{c}\text { Artigo: Yee; Sansó e Cano (2018); Formoso, Rodríguez e Rodríguez } \\
\text { (2017); Rodríguez et al. (2015) } \\
\text { TCC: Vega; Morales e Chacón (2018) }\end{array}$ & 4 \\
\hline $\begin{array}{l}\text { Juegos } \\
\text { Analógicos (o } \\
\text { Tablero) y } \\
\text { Pérdida de } \\
\text { Audición }\end{array}$ & & 0 \\
\hline \multicolumn{2}{|c|}{ Total de Trabalhos Acadêmicos Vinculado aos Jogos Analógicos (ou Tabuleiro) } & 30 \\
\hline
\end{tabular}

Fonte: Autores

De forma geral, no que se refere aos jogos digitais, Ramos, Melo e Mattar (2018, p. 673) afirma que "o uso das tecnologias digitais no contexto escolar de maneira intencional na escola cria condições para o desenvolvimento de habilidades cognitivas fundamentais à aprendizagem, que podem ser aprimoradas por meio da experiência e da interação social". Contudo, mesmo que a literatura demonstre a relevância dos jogos digitais para o processo de ensino-aprendizagem, o caminho de inclusão desses recursos para estudantes que se diferem do padrão biologizante corriqueiramente empregado nos espaços de ensino, como no caso dos estudantes surdos, ainda é uma pauta distante de sua efetividade.

Nesse sentido, Cheiran (2013), complementa a discussão sugerindo que a acessibilidade quanto à adoção dos jogos digitais, para usuários (estudantes) de distintas condições físico-cognitivas, perpassa fatores de ordem arquitetônica (do próprio jogo em questão), comunicacional (quanto à aceitação do próprio usuário) e, principalmente, nas esferas atitudinais e instrumentais, ou seja, como o praticante, no caso o profissional docente, se utiliza do jogo 
para um objetivo educacional. Em suma, Cheiran (2013, p. 29-30) afirma ainda que "[...] a acessibilidade atitudinal é relacionada ao atendimento adequado das pessoas com necessidades especiais [enquanto] a acessibilidade instrumental está relacionada às ferramentas e ao seu uso" que esteja a par das demandas e condições específicas do público em questão.

Desta forma, mesmo que a adoção de jogos digitais sejam uma das tônicas ligadas a elaboração de ferramentas pedagógicas no mundo digital (LEVY, 2010) contemporâneo, fatores como o alto investimento na criação e na adoção desses artefatos culturais (RODRIGUES; ALVES, 2014) criam obstáculos para a sua implementação em espaços formativos e, por consequência, em pesquisas acadêmicas. Além disso, a própria dificuldade de modificação na estrutura geral do jogo em si, ou seja, nas mecânicas, gráficos e recursos pré-definidos na produção inicial, limitam a adoção direta, sem adaptações profundas por parte do profissional de ensino em questão, principalmente quando tais adaptações precisam articular demandas, no caso específico deste estudo, de estudantes surdos e ouvintes em uma mesma sala de aula.

Contudo, em 24 trabalhos analisados foi possível identificar uma série de exemplos de ações em espaços formativos com a presença de estudantes surdos e ouvintes no qual os jogos digitais, mesmo diante das limitações suscitadas, foram adotados com as devidas adaptações que privilegiem ambos os públicos (CANO et al., 2018a; CANO et al., 2015; WAKI; FUJIYOSHI; ALMEIDA, 2015). Entretanto, como mencionado, essa conduta por parte do corpo docente dependerá das atitudes adotadas por esses profissionais e, é claro, da própria (e já sinalizada) infraestrutura e demais condições de trabalho que dificultam a prática docente.

Inserido nesse contexto estão os jogos de tabuleiro, que diferente das versões digitais, não são, em sua maioria, limitados pelas estruturas internas contidas no próprio jogo (HUIZINGA, 2000). A possibilidade de variação, adaptação e efetividade perante o objetivo educacional principal está limitada pela forma no qual o jogo vai se apresentar, seja por conta do mediador (o professor) e os receptores (os estudantes) da ação. Outros fatores que podem justificar a identificação de mais trabalhos acadêmicos vinculados aos jogos analógicos com o ensino de estudantes surdos partem tanto do menor custo na compra e/ou construção dos mesmos como ferramentas didáticas (CHEIRAN, 2013), quanto a acessibilidade e familiaridade do professor com diferentes gerações de jogos analógicos facilitam a adoção desses na prática de ensino, principalmente, ao que se refere a profissionais de ensino que não nativos digitais (RODRIGUES; ALVES, 2014).

Contudo, um ponto de associação entre os jogos digitais e analógicos, identificado durante a análise do corpus deste estudo, refere-se ao enfoque dado na maioria dos trabalhos às questões de ordem da saúde humana (CORREDOR; CARDONA; GALLO, 2015), ou seja, objetivos de pesquisa que por vezes atribuía uma lente voltada de análise das características e valores, principalmente, da aprendizagem dos estudantes surdos com um viés padronizador, se aproximando de perspectivas medicalizante ou biologizantes do indivíduo surdo. A adoção de expressões como deficientes auditivos (principalmente em trabalhos fora do Brasil) e dentre outras denominações com foco na condição da surdez como limitador à aprendizagem, de certo modo, 
deturpam o objetivo deste artigo que é voltado para a ambientação e inclusão dos estudantes surdos a partir das próprias demandas características da diversidade contida em salas de aula, ignorando, portanto, a adoção dos jogos como recursos passíveis de lidar com limitações.

Por conta dessa característica sinalizada, muitos trabalhos analisados, como o de Bierre et al. (2014) e Yuan; Folmer e Harris (2011), associam o uso dos jogos digitais e analógicos de forma indistinta perante estudantes surdos, cegos e/ou mudos. Contudo, esse tipo de associação, sem estabelecer as reais demandas e subjetividades de cada um dos grupos apontados anteriormente, leva a uma reprodução, segundo Witkoski (2009, p. 565), de "história do povo surdo quanto às marcas que o identificam [erroneamente] como um ser incompleto, incapaz, deficiente [...] a partir dessa concepção da surdez, todo tipo de violência física e simbólica foi exercida" e, ainda é, de forma indireta quando não é considerada a própria identidade de cada indivíduo surdo.

Para finalizar, outro importante dado a ser apresentado refere-se ao número considerável de trabalhos acadêmicos identificados na categoria de jogos digitais que se utilizam dos mesmo a partir dos princípios dos denominados Serious Games. Esses jogos digitais podem ser separados dos demais por conta do "foco em um resultado de aprendizado específico e intencional para alcançar mudanças de performance e comportamento sérios, mensuráveis e continuados" (CARRYBERRY 2008 apud ARAUJO; STEIN; ROMÃO, 2012, grifo nosso). Nesse sentido, tais jogos digitais não são direcionados necessariamente ao entretenimento, mas se utilizam do mesmo (para cativar os usuários/estudantes) em prol de metas ligadas à obtenção de competências nos mais variados campos do saber.

Em suma, a abordagem voltada para os Serious Games foi base norteadora em 13 trabalhos acadêmicos do total de 24 estudos articulados com os jogos digitais e o ensino de estudantes surdos identificados, sendo todos eles produzidos fora do Brasil. Desta forma, com base na literatura analisada, se sugere que a implementação de ações com os jogos digitais, que favoreçam o processo de ensino-aprendizagem de estudante surdos, demanda a utilização dos Serious Games, oportunizando assim, que experiências como as vivenciadas por Cano et al. (2018b, p. 83) possam servir de exemplo de "modelos a serem adaptados de forma útil para identificar as necessidades relevantes para apoiar crianças surdas e professores", na construção de planejamentos e propostas pedagógicas que articulem o digital de forma satisfatória com as subjetividades da própria Cultura Surda.

\section{APRESENTAÇÃO DOS DESIGNERS PEDAGÓGICOS PROPOSTOS}

Como suscitado anteriormente, a construção de planos de intervenção que associem os recursos pedagógicos adotados com uma prática de ensino atenta às demandas de todos os diferentes grupos estudantis em sala de aula é essencial. Nesse sentido, este artigo apresenta em seu último tópico dois modelos de intervenções pedagógicas passíveis de serem adotadas em diferentes espaços de ensino regulares com estudantes surdos a partir das orientações nacionais que norteiam a Educação de Surdos no país (BRASIL, 1996; 2002; 2005; 2010). 


\section{Modelo da Intervenção Libras em Cena}

Esta intervenção se baseou no uso de dois Jogos Analógicos (Libras em Jogo e É Proibido Falar), jogos esses passíveis de serem encontrados em lojas física e/ou online. A escolha por Jogos Analógicos já comercializados no mercado nacional ao invés da construção do próprio artefato lúdico se deve por algumas razões.

Em suma, o setor de Jogos Analógicos no Brasil vem crescendo segundo a Associação Brasileira de Fabricantes de Brinquedos (2019), tornando tais jogos mais acessíveis, inclusive no âmbito financeiro para os consumidores. No caso do corpo docente, mesmo que existam plataformas virtuais, como o Banco Internacional de Objetos Educacionais disponibilizado pelo Ministério da Educação e Cultura (MEC), a falta de tempo e a necessidade de gastos anuais ou semestrais com a confecção dos materiais presentes nessas plataformas prejudicam o uso contínuo desses jogos no ambiente escolar.

Nesse sentido é possível sistematizar tais jogos da seguinte maneira:

a) Libras em Jogo é um jogo produzido pela Universidade da Libras tendo como base a Escrita de Sinais (SignWriting) no qual cada carta tem uma foto da Configuração de Mão e a escrita de sinais correspondente. $O$ intuito do jogo (voltado tanto para surdos como para ouvintes) é desenvolver a prática da Língua Brasileira de Sinais (Libras) a partir da construção de novos sinais, aprofundando os que já sabe e formando frases completas apenas utilizando as cartas do jogo.

Figura 1: Imagens do instrumento adotado Libras em Jogo

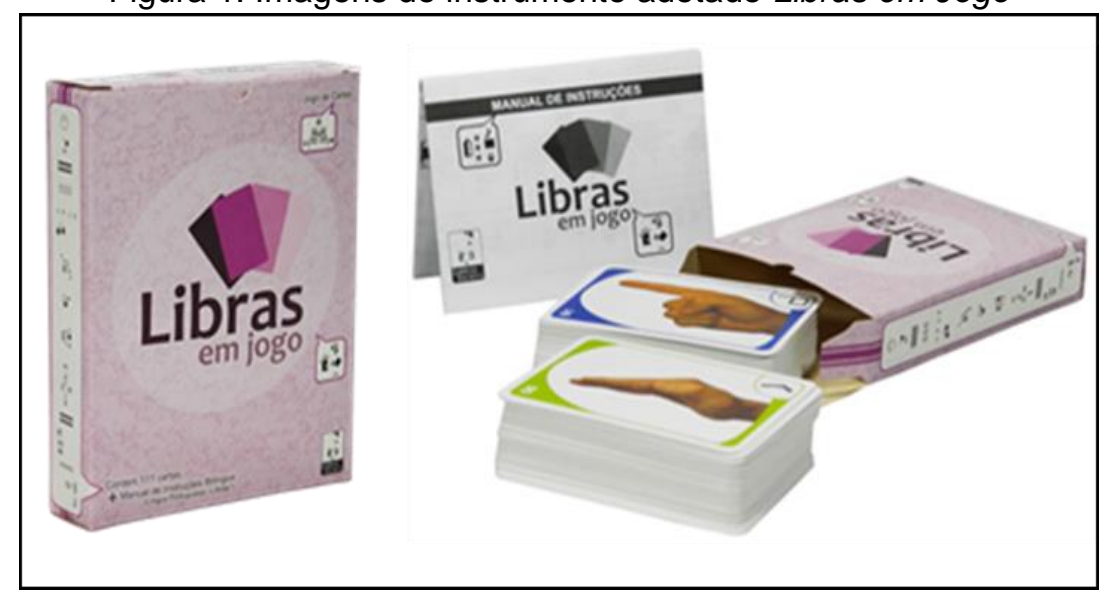

Fonte: Universidade da Libras (https://universidadedalibras.com.br)

b) É Proibido Falar é um jogo produzido pela Grow $\Theta$ tendo como base o uso de mímicas ou sinais para revelar para os demais jogadores qual a palavra selecionada. No contexto da pesquisa, as regras do jogo serão adaptadas de forma a obrigar que os jogadores ao invés de usarem mímicas ou sinais sem significado aparente passem a utilizar os sinais da Libras aprendidos durante a prática do Libras em Jogo vinculando esses sinais a conteúdos trabalhados em sala de aula. O intuito do É Proibido Falar se baseia na utilização da memória e da criatividade perante a nova língua apresentada, favorecendo assim a interação e participação tanto de estudantes surdos como ouvintes ao mesmo tempo durante as partidas do jogo. 
Figura 2: Imagens do jogo adotado É Proibido Falar

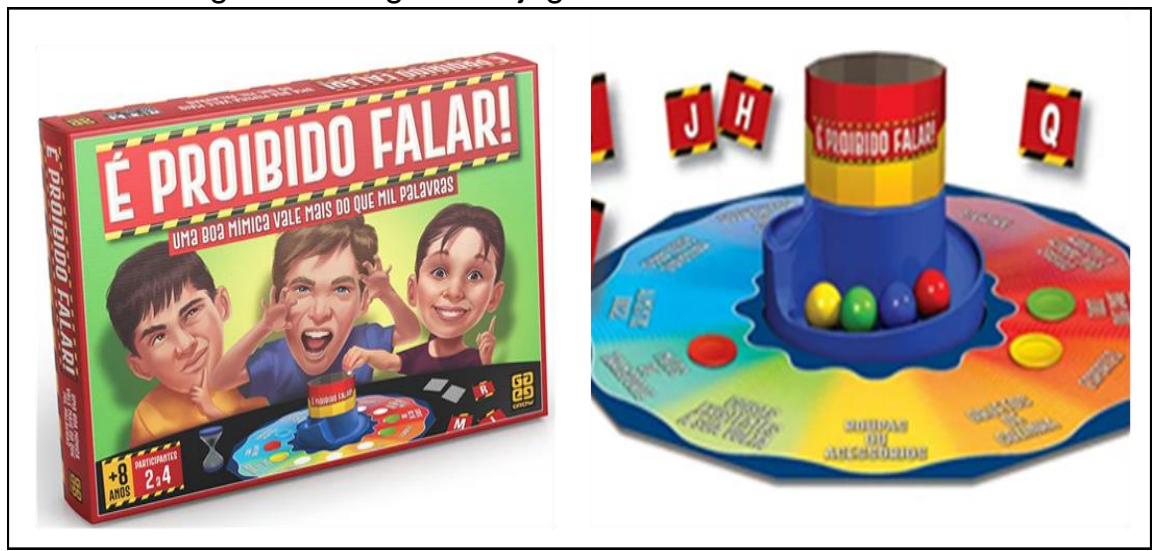

Fonte: Loja Grow (https://www.lojagrow.com.br/jogo-e-proibido-falar/p)

Desta forma, seguindo a própria arquitetura de cada um dos jogos apresentados sugere-se um modelo de intervenção que possa ser empregado em diferentes níveis escolares, respeitando as singularidades quanto à mediação e à aprendizagem (VYGOTSKY, 1988) de cada estudante. Os recursos e estratégias didáticas adotadas a seguir sintetizam as dificuldades identificadas na análise do corpus selecionado durante a revisão sistemática, além de aproveitar as principais experiências presentes em tais estudos.

Quadro 2: Modelo de intervenção Libras em Cena

\begin{tabular}{|c|l|}
\hline Professor(a): & $\begin{array}{l}\text { Grupo Alvo: Pode ser aplicado, dependendo do conteúdo escolhido, } \\
\text { desde o Ensino Fundamental I até o Ensino Médio }\end{array}$ \\
\hline Temática Central & $\begin{array}{l}\text { Adoção de jogos analógicos no processo de ambientação e ensino- } \\
\text { aprendizagem de estudantes surdos }\end{array}$ \\
\hline $\begin{array}{c}\text { Pergunta e } \\
\text { Relevância da } \\
\text { Temática }\end{array}$ & $\begin{array}{l}\text { Qual é o questionamento que será promovido durante a intervenção? } \\
\text { Tanto a pergunta central como a relevância devem partir dessa } \\
\text { questão motive o estudante (BEHAR, 2009) }\end{array}$ \\
\hline $\begin{array}{c}\text { Duração da } \\
\text { Intervenção }\end{array}$ & $\begin{array}{l}\text { a) Intervenção (100 minutos, equivalente a duas aulas regulares na } \\
\text { Educação Básica) }\end{array}$ \\
\hline $\begin{array}{c}\text { Objetivo Geral da } \\
\text { Intervenção }\end{array}$ & $\begin{array}{l}\text { Ao final da intervenção espera-se que os estudantes possam } \\
\text { experimentar uma proposta ensino de caráter lúdico vinculado à } \\
\text { aprendizagem de conteúdos de Biologia a partir do uso da Libras. }\end{array}$ \\
\hline $\begin{array}{c}\text { Conteúdos } \\
\text { Utilizados }\end{array}$ & $\begin{array}{l}\text { Dependendo da etapa de ensino do docente a escolha do conteúdo } \\
\text { poderá ser realizada a partir dos documentos: Base Nacional Comum } \\
\text { Curricular (2017); Orientações Curriculares Nacionais do Ensino Médio } \\
\text { (2006); Parâmetros Curriculares Nacionais + (2000) e Diretrizes } \\
\text { Curriculares Nacionais para o Ensino Fundamental (2013). }\end{array}$ \\
\hline $\begin{array}{c}\text { Sugestões de } \\
\text { Estratégias de } \\
\text { Ensino a Serem } \\
\text { Utilizadas }\end{array}$ & $\begin{array}{l}\text { a) Explicação da atividade através de apostila informativa para os } \\
\text { estudantes. } \\
\text { b) Exposição de vídeo síntese (em Libras ou legendado) sobre os } \\
\text { conteúdos a serem trabalhados em sala de aula } \\
\text { c) Uso do jogo Libras em Jogo adaptando os sinais disponíveis nas nara a memorização de termos e conceitos discutidos na } \\
\text { cartas para a } \\
\text { intervença (Atividade Cooperativa entre os estudantes - surdos e } \\
\text { ouvintes). }\end{array}$ \\
\hline
\end{tabular}




\begin{tabular}{|c|c|}
\hline & $\begin{array}{l}\text { d) Uso do jogo É Proibido Falar no qual os participantes precisarão } \\
\text { usar os mesmos sinais aprendidos na atividade anterior, contudo desta } \\
\text { vez sem o uso das cartas como auxílio (Atividade Competitiva entre } \\
\text { os estudantes - formação de duplas, trios ou equipes com estudantes } \\
\text { surdos juntamente com estudantes ouvintes) } \\
\text { d) Após finalizados os jogos, os estudantes serão convidados a } \\
\text { escreverem (Individualmente) uma síntese sobre o que foi aprendido } \\
\text { em sala de aula. }\end{array}$ \\
\hline $\begin{array}{l}\text { Recursos } \\
\text { Didáticos e } \\
\text { Materiais }\end{array}$ & $\begin{array}{l}\text { Projetor Multimídia (ou Notebook para exibição do vídeo) ou apostila } \\
\text { explicativa ou reportagens impressas sobre o tema a ser discutido; } \\
\text { pilotos (marcadores de quadro); Jogos (Libras em Jogo e É Proibido } \\
\text { Falar). }\end{array}$ \\
\hline $\begin{array}{c}\text { Design } \\
\text { Pedagógico } \\
\text { voltado para } \\
\text { estudantes } \\
\text { surdos } \\
\text { (BEHAR, 2009) }\end{array}$ & $\begin{array}{l}\text { a) Fatores Técnicos: O uso da Libras como principal canal de } \\
\text { comunicação permite, no âmbito técnico, que possa ser suscitada a } \\
\text { interação entre estudantes surdos e ouvintes em sala de aula } \\
\text { b) Fatores Gráficos: Os jogos analógicos escolhidos, além de usarem o } \\
\text { próprio canal de comunicação (Libras) como principal linguagem das } \\
\text { dinâmicas, eles também possuem regras simples e um design atrativo } \\
\text { para qualquer idade. } \\
\text { c) Fatores Pedagógicos: Segue a proposta interacionista de Vygotsky } \\
\text { (1988), além dos pressupostos pautados na Aprendizagem Baseada } \\
\text { em Problemas (CONRADO; NUNES-NETO, 2018). }\end{array}$ \\
\hline Referências & $\begin{array}{l}\text { As referências a serem adotadas, além das orientações nacionais para } \\
\text { educação, deverão acompanhar as especificidades área em questão. }\end{array}$ \\
\hline
\end{tabular}

Fonte: Autores

\section{Modelo da intervenção Link para a Diversidade}

A adoção de jogos digitais, independentemente da plataforma ou mídia em questão (através do computador, plataformas de videogame e/ou celular), configura-se como uma ação corriqueira nos últimos anos perante o avanço do próprio mundo digital (LEVY, 2010) no dia a dia de estudantes e demais partícipes do ambiente escolar. Contudo, a utilização desses artefatos culturais se restringe à instrumentalização do mesmo, sem a devida problematização, no âmbito pedagógico, dos conteúdos e saberes trabalhados sob a égide da própria ferramenta.

Nesse sentido, os jogos digitais, por vezes, são relegados a uma associação direta do objetivo do jogo com o conteúdo trabalho em sala. Essa dinâmica limita a participação do corpo estudantil, fazendo-o seguir mecanicamente o que está proposto, sem estimular a interação desses estudantes com as opiniões, perspectivas e subjetividades de cada um sobre 0 tema apresentado.

Desta forma, o segundo modelo de intervenção proposto por este estudo toma como base o jogo gratuito denominado Never Alone (Kisima Ingitchuna). Esse jogo foi criado pela empresa Upper One Games para todas as plataformas (computador, smartphones e consoles) de forma gratuita no ano de 2014. A narrativa do jogo foi desenvolvida em parceria com nativos da região do Alasca (EUA) ao contar uma história de amizade entre uma menina (protagonista) com um lobo, ambos rejeitados por suas "famílias" e que precisam juntos lidar com diversas situações de perigo. 
Em síntese, a narrativa explora os saberes tradicionais do povo Inupiat localizados no Ártico, acerca de dois personagens com culturas, saberes e pontos de vista diferentes. É a partir dessa diferença o(a) jogador(a), no caso em questão, os estudantes, precisarão compreender que essa diferença não é um obstáculo, mas a solução para transpor diversos desafios e, por que não salientar também, por inúmeros preconceitos.

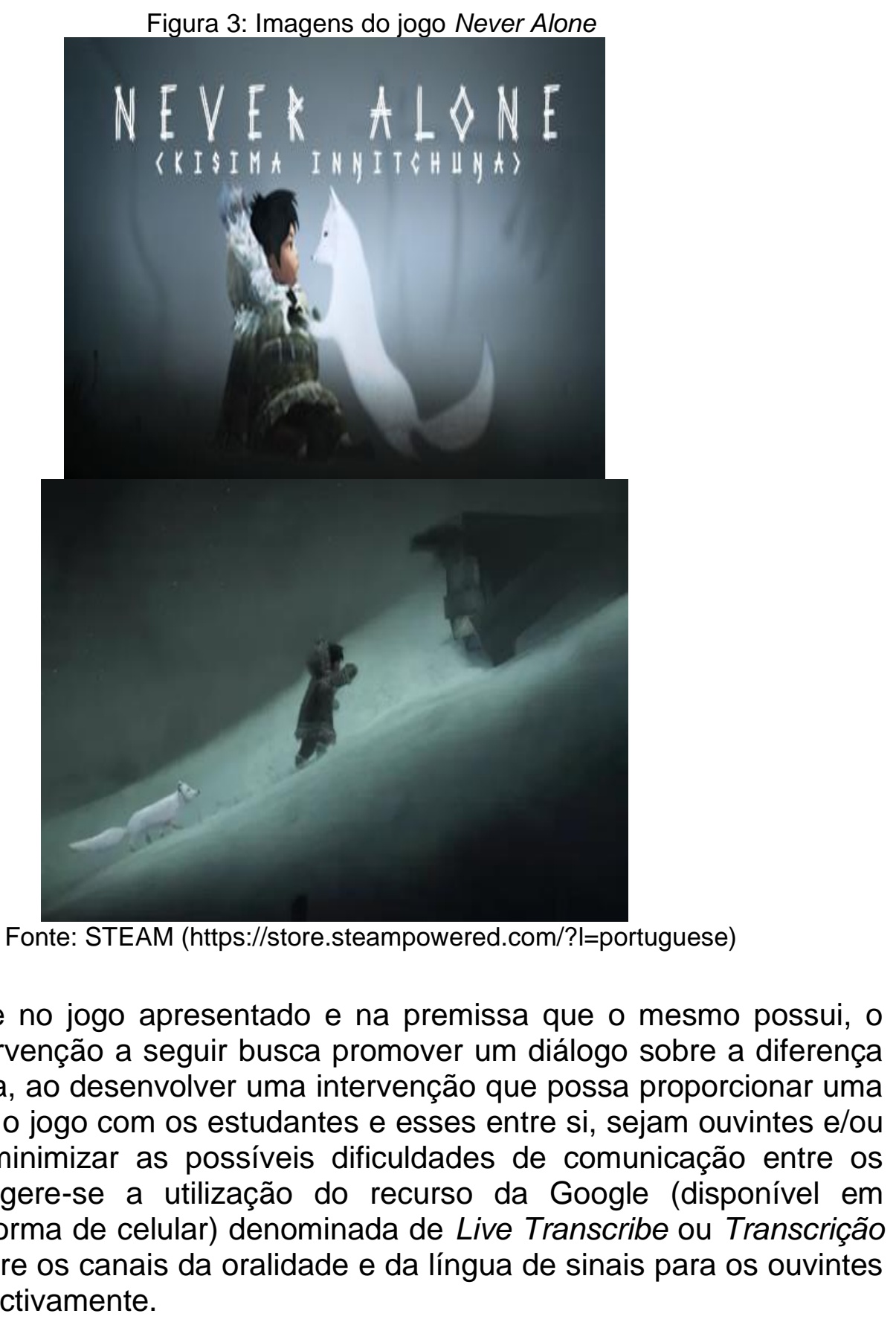

Com base no jogo apresentado e na premissa que o mesmo possui, o modelo de intervenção a seguir busca promover um diálogo sobre a diferença em sala de aula, ao desenvolver uma intervenção que possa proporcionar uma interação entre o jogo com os estudantes e esses entre si, sejam ouvintes e/ou surdos. Para minimizar as possíveis dificuldades de comunicação entre os estudantes, sugere-se a utilização do recurso da Google (disponível em qualquer plataforma de celular) denominada de Live Transcribe ou Transcrição Instantânea entre os canais da oralidade e da língua de sinais para os ouvintes e surdos, respectivamente. 
Quadro 3: Modelo de intervenção Link para a Diversidade

\begin{tabular}{|c|c|}
\hline Professor(a): & $\begin{array}{l}\text { Grupo Alvo: Pode ser aplicado, preferencialmente, para estudantes do Ensino } \\
\text { Fundamental Il e Ensino Médio }\end{array}$ \\
\hline $\begin{array}{l}\text { Temática } \\
\text { Central }\end{array}$ & Respeito ao multiculturalismo (CANDAU, 2008) presente em sala de aula \\
\hline $\begin{array}{l}\text { Pergunta e } \\
\text { Relevância da } \\
\text { Temática }\end{array}$ & $\begin{array}{l}\text { Qual é o questionamento que será promovido durante a intervenção? Tanto a } \\
\text { pergunta central como a relevância devem partir dessa questão motive o } \\
\text { estudante (BEHAR, 2009) }\end{array}$ \\
\hline $\begin{array}{l}\text { Duração da } \\
\text { Intervenção }\end{array}$ & $\begin{array}{l}\text { a) Intervenção (100 minutos, equivalente a duas aulas regulares na Educação } \\
\text { Básica) }\end{array}$ \\
\hline & $\begin{array}{l}\text { Ao final da intervenção espera-se que os estudantes surdos/ouvintes possam ter } \\
\text { interagido entre si e com o professor a partir da temática trabalhada. }\end{array}$ \\
\hline $\begin{array}{l}\text { Conteúdos } \\
\text { Utilizados }\end{array}$ & $\begin{array}{l}\text { Dependendo da etapa de ensino do docente a escolha do conteúdo poderá ser } \\
\text { realizada a partir dos documentos: Base Nacional Comum Curricular (2017); } \\
\text { Orientações Curriculares Nacionais do Ensino Médio (2006); Parâmetros } \\
\text { Curriculares Nacionais + (2000) e Diretrizes Curriculares Nacionais para o } \\
\text { Ensino Fundamental (2013) }\end{array}$ \\
\hline $\begin{array}{l}\text { Sugestões de } \\
\text { Estratégias de } \\
\text { Ensino a } \\
\text { Serem } \\
\text { Utilizadas }\end{array}$ & $\begin{array}{l}\text { a) Explicação da atividade através de apostila informativa para os estudantes. } \\
\text { b) Exposição do vídeo da TV INES sobre o Multiculturalismo da autora Vera } \\
\text { Lúcia Candau (https://www.youtube.com/watch?v=2C4SDzwPJZO) em áudio, } \\
\text { Libras e legenda. } \\
\text { c) Exposição do trailer do jogo Never Alone (em Libras ou legendado) } \\
\text { d) Divisão dos estudantes em grupos no qual cada um terá um representante } \\
\text { jogando o próprio jogo. Sugere-se que os grupos sejam formados por ouvintes e } \\
\text { surdos. } \\
\text { e) Cada grupo precisará ao término do tempo destinado ao jogo salientar as } \\
\text { percepções acerca do mesmo e do tema discutido, o multiculturalismo. }\end{array}$ \\
\hline $\begin{array}{l}\text { Recursos } \\
\text { Didáticos e } \\
\text { Materiais }\end{array}$ & $\begin{array}{l}\text { Celulares (configurações mais simples, pelo um por grupo, não precisa de } \\
\text { internet); apostila explicativa; projetor multimídia para expor o vídeo pilotos } \\
\text { (marcadores de quadro); uso do Jogo Never Alone e do aplicativo Live } \\
\text { Transcribe. }\end{array}$ \\
\hline $\begin{array}{l}\text { Design } \\
\text { Pedagógico } \\
\text { voltado para } \\
\text { estudantes } \\
\text { surdos } \\
\text { (BEHAR, 2009) }\end{array}$ & $\begin{array}{l}\text { a) Fatores Técnicos: A interação entre o uso da Libras e da oralidade por parte } \\
\text { dos estudantes ouvintes com os estudantes surdos fundamentam a mecânica da } \\
\text { intervenção. } \\
\text { b) Fatores Gráficos: O jogo escolhido, mesmo que possua trilha sonora a } \\
\text { percepção gráfica do mesmo é o que proporciona a experiência maior por parte } \\
\text { dos estudantes, além de atrelar a dinâmica a uma ferramenta digital corriqueira } \\
\text { na contemporaneidade. } \\
\text { c) Fatores Pedagógicos: O jogo Never Alone carrega um conjunto de temas } \\
\text { sobre respeito a diferença e da diversidade como fator essencial para alcançar } \\
\text { os objetivos do jogo, buscando nessa cooperação um diálogo sobre questões } \\
\text { que envolvam a Cultura Surda e a ambientação dos estudantes surdos. }\end{array}$ \\
\hline Referências & $\begin{array}{l}\text { As referências devem ser voltadas para Educação de Surdos e o } \\
\text { Multiculturalismo }\end{array}$ \\
\hline
\end{tabular}

Fonte: Autores

\section{CONSIDERAÇÕES FINAIS}

O estudo, através das diferentes formas de análise do objeto investigado, procurou apresentar experiências e possibilidades de intervenções que possam figurar na prática docente em salas de aula regulares com tenham a presença 
de estudantes surdos. As experiências aqui retratadas sejam através dos jogos digitais, a partir dos denominados Serious Games, ou via jogos analógicos, que apostam no potencial de adaptação dos mesmos aos diferentes objetivos de ensino, demonstram que a adoção desses artefatos culturais é possível e profícua de serem implementos em diversas situações que envolvam a articulação entre estudantes surdos e ouvintes.

Contudo é importante sinalizar que a utilização desses instrumentos pedagógicos não deve ser relegada a um mero utensílio de ensino, desvinculado com as distintas demandas dos grupos de estudantes presentes em sala de aula. $O$ uso dos jogos precisa estar atrelado com a real necessidade do ambiente formativo e de acordo, é claro, com as próprias condições infraestruturais do espaço em questão. É necessário, portanto, que os jogos, em ambas as arquiteturas funcionais (digital ou analógico), possam se integrar de forma orgânica aos planejamentos de aula, promovendo simultaneamente a ambientação e a interação desses estudantes surdos na prática docente diária.

Desta forma, afirmar-se que os jogos digitais e analógicos vêm sendo adotados no ambiente formativo, permitindo que os estudantes surdos e conjunto com os estudantes ouvintes experimentem estratégias pedagógicas diversificadas e significativas para o processo de aprendizagem. Entretanto, muitas dessas experiências analisadas a partir da revisão da literatura permitiu identificar ainda muitos estudos imersos em uma abordagem que medicaliza o estudante surdo, atendendo-se a ele como deficiente, denominações e ações que vão de encontro à história de luta das comunidades surdas e das próprias características que edificam a Cultura Surda nos diferentes agrupamentos culturais espalhados pelo mundo.

Nesse sentido, espera-se que estudos como este possam estimular ações que promovam um diálogo direto entre as demandas dos estudantes surdos em sala de aula, sem desenvolver a clássica inclusão que exclui e categoriza o surdo como um indivíduo limitado. Dessa forma, trabalhos, inclusive, que implementem os modelos de intervenção aqui propostos possam ser desenvolvidos em diferentes espaços de ensino aqui no Brasil. Um país que ainda luta pelo respeito da sua própria diversidade cultural, uma pluralidade cultural capaz de engrandecer o processo de ensino ao longo das diferentes etapas educacionais, mas que no presente momento ainda é considerado como fonte de mais obstáculos, restringindo assim as potencialidades contidas em grupos culturais, como é o caso dos estudantes surdos. É preciso então observar o espaço de ensino com a criatividade e riqueza inerente às subjetividades contidas na própria Cultura Surda.

\section{REFERÊNCIAS}

ABRIN. Setor de brinquedos encerra 2018 com 7,5\% de crescimento. 2019.

Disponível em: <https://www.abrin.com.br/pt-br/press-release2/539-setor-debrinquedos-encerra-2018-com-7-5-de-crescimento>. Acesso: julho, 2019.

ARAUJO, Maicon Hackenhaar de; STEIN, Mônica; ROMÃO, João Jair da Silva. Jogo e serious games: conceito e bons princípios para análise do jogo SpaceCross, da Volkswagen. In: SBGAMES, 11, 2012, Brasília (DF). Anais Eletrônicos... Brasília: Art \& Design Track, 2012. Disponível em: 
<http://sbgames.org/sbgames2012/proceedings/papers/artedesign/AD_Short1.pdf>. Acesso em: 5 jul. 2019.

BALCEDA, Fernando David. Deafquiz: un juego educativo que integra niños sordos y oyentes en el proceso de aprendizaje de la Lengua de Señas. 85f. Trabalho de Conclusão de Curso (Licenciatura). Facultad de Informática, La Plata, Argentina, 2017. Disponível em: <http://sedici.unlp.edu.ar/handle/10915/71301>. Acesso em: 7 jul. 2019.

BANDEIRA, Denise. Material didático: conceito, classificação geral e aspectos da elaboração. Curso de Materiais didáticos para smartphone e tablet. Curitiba, IESDE, p. 13-33, 2009. Disponível em: <http://www2.videolivraria.com.br/pdfs/24136.pdf>. Acesso em: 10 jul. 2019.

BAQUETA, Jeferson José. Especificação e protótipo de um jogo educativo para aprendizagem de conceitos por crianças surdas. 109f. Trabalho de Conclusão de Curso (Bacharelado), Universidade Estadual do Oeste do Paraná, Paraná, Brasil, 2012. Disponível em: <http://www.inf.unioeste.br/ tcc/2012/TCC_Jeferson.pdf>. Acesso em: 4 jul. 2019.

BARBOSA, Jonei Cerqueira. Abordagens teóricas e metodológicas na Educação Matemática: aproximações e distanciamentos. In: REUNIÃO NACIONAL DA ANPED, 38, 2017, São Luís (MA). Anais Eletrônicos... São Luís: ANPed, 2017. Disponível em: $<$ http://38reuniao.anped.org.br/sites/default/files/resources/programacao/trabalhoenco m_38anped_2017_gt19_jonei_cerqueira_barbosa.pdf >. Acesso em: 12 jul. 2019.

BARBOSA, Josilene Souza Lima. A tecnologia assistiva digital na alfabetização de crianças surdas. 195f. Dissertação (Mestrado) - Universidade Federal do Sergipe. Programa de Pós-graduação em Educação. São Cristóvão, Sergipe, Brasil, 2011. Disponível em: <http://ri.ufs.br/jspui/handle/riufs/4722>. Acesso em: 12 jul. 2019.

BEHAR, Patricia Alejandra. Modelos pedagógicos na educação a distância. Porto Alegre: Artmed, p. 33-65, 2009.

BIERRE, K. et al. Game not over: Accessibility issues in video games. In: INTERNATIONAL CONFERENCE ON UNIVERSAL ACCESS IN HUMANCOMPUTER INTERACTION, 3, 2005, Las Vegas, Nevada, USA. Anais Eletrônicos... Las Vegas: Games Accessibility Special Interest Group, 2005. Disponível em: <https://www.researchgate.net/profile/Kevin_Bierre/publication/267403944_Game_Not _Over_Accessibility_Issues_in_Video_Games/links/546de0d70cf2a7492c560d87.pdf >. Acesso em: 9 jul. 2019.

BISOGNIN, Eleni. Produtos educacionais: análise da produção do Mestrado Profissional em Ensino de Física e de Matemática do Centro Universitário Franciscano de Santa Maria, Rio Grande do Sul, Brasil. Revista Polyphonía, v. 24, n. 2, p. 43-58, jul./dez. 2013. Disponível em: <https://www.revistas.ufg.br/sv/article/view/37938>. Acesso: 1 jul. 2019.

BRASIL. Lei $n$. 9 9.394, de 20/12/1996. Estabelece a lei de diretrizes e bases da educação nacional. Brasília: Ministério da Educação, 1996. Disponível em: <http://www.planalto.gov.br/ccivil_03/leis/l9394.htm>. Acesso em: 11 jul. 2019.

BRASIL. Lei no 10.436, de 24 de abril de 2002. Dispõe sobre a Língua Brasileira de Sinais-Libras e dá outras providências. Diário Oficial da União, 2002. Disponível 
em: <http://www.planalto.gov.br/ccivil_03/leis/2002//10436.htm>. Acesso em: 15 jul. 2019.

BRASIL. Ministério da Educação. Parâmetros Curriculares Nacionais + para o Ensino Médio. Brasília, 2000. Disponível em:

<http://portal.mec.gov.br/seb/arquivos/pdf/blegais.pdf> Acesso em: 11 jul. 2019.

BRASIL. Decreto no 5626 de 22 de dezembro de 2005. Brasília: Presidência da República, 2005. Disponível em: <http://www.planalto.gov.br/ccivil_03/_Ato20042006/2005/Decreto/D5626.htm>. Acesso em: 12 jul. 2019.

BRASIL. Ministério da Educação. Orientações Curriculares Nacionais. Brasília, 2006. Disponível em:

<http://portal.mec.gov.br/seb/arquivos/pdf/book_volume_01_internet.pdf>. Acesso em: 14 jul. 2019.

BRASIL. Lei $n^{\circ} 12.319$, de $1^{\circ}$ de setembro de 2010. Regulamenta a profissão de Tradutor e Intérprete da Língua Brasileira de Sinais - LIBRAS. Brasília, 2010. Disponível em: <http://www.planalto.gov.br/ccivil_03/_Ato20072010/2010/Lei/L12319.htm>. Acesso em: 10 jul. 2019.

BRASIL. Ministério da Educação. Diretrizes Curriculares Nacionais para o Ensino Fundamental. Brasília, 2013. <http://portal.mec.gov.br/docman/julho-2013-pdf/13677diretrizes-educacao-basica-2013-pdf/file>. Acesso: Acesso em: 21 jul. 2019.

BRASIL. Ministério da Educação. Conselho Nacional de Educação. Resolução CNE/CP № 2, de 22 de dezembro de 2017, que institui a Base Nacional Comum Curricular. Brasília, 2017. Disponível em:

<http://basenacionalcomum.mec.gov.br/images/historico/RESOLUCAOCNE_CP222D EDEZEMBRODE2017.pdf>. Acesso em: 18 jul. 2019.

CAILLOIS, Roger. Os jogos e os homens: a máscara e a vertigem. São Paulo: Vozes, 2017.

CALDAS, Ana Luiza Paganelli. Narrativas de professores de surdos sobre a EJA no município de Porto Alegre/RS. Cadernos de Pesquisa. v. 23, n. 2, p. 46-57, mai./ago. 2016. Disponível em: <https://www.lume.ufrgs.br/handle/10183/163435>. Acesso em: 25 jun. 2019.

CALDEIRA, Verônica Lima de Almeida; SOUZA, Danielly Barbosa de; ANANIAS, Eliane Farias. Do giro ao ângulo: uma experiência com alunos surdos bilíngues. In: ENCONTRO NACIONAL DE EDUCAÇÃO MATEMÁTICA, 11, 2013, Curitiba (PR), Brasil. Anais Eletrônicos... Curitiba: SBEM, 2013. Disponível em: <http://sbem.iuri0094.hospedagemdesites.ws/anais/XIENEM/pdf/1369_1038_ID.pdf>. Acesso em: 12 jul. 2019.

CAMPELLO, Ana Regina e Souza. Pedagogia visual na educação dos surdosmudos. 169f. Tese (Doutorado), Universidade Federal de Santa Catarina, Brasil, 2008. Florianópolis: UFSC, 2008. Disponível em: <https://cultura-sorda.org/wpcontent/uploads/2015/04/Tesis_Souza_Campello_2008b.pdf>. Acesso em: 20 jun. 2019. 
em: <https://www.e-publicacoes.uerj.br/index.php/riae/article/view/24888/17854>. Acesso em: 15 jun. 2019.

CANDAU, Vera Maria. Direitos humanos, educação e interculturalidade: as tensões entre igualdade e diferença. Revista Brasileira de educação, v. 13, n. 37, p. 45-56, jan./abr. 2008. Disponível em: <http://www.scielo.br/pdf/rbedu/v13n37/05.pdf>. Acesso em: 10 jun. 2019.

CANO, S. et al. Model for analysis of serious games for literacy in deaf children from a user experience approach. In: INTERNATIONAL CONFERENCE ON HUMAN COMPUTER INTERACTION, 16, 2015, Vilanova, Espanha. Anais Eletrônicos... Vilanova: ACM, 2015. Disponível em: <https://dl.acm.org/citation.cfm?id=2829885>. Acesso em: 6 jul. 2019.

CANO, S. et al. Toward a methodology for serious games design for children with auditory impairments. IEEE Latin America Transactions, v. 14, n. 5, p. 2511-2521, mai. 2016a. Disponível em: <https://ieeexplore.ieee.org/abstract/document/7530453>. Acesso em: 10 jul. 2019.

CANO, S. et al. Design of a set Serious mini-games as support in cognitive rehabilitation for Children with Auditory Impairment. In: WORKSHOP ON ICTS FOR IMPROVING PATIENTS REHABILITATION RESEARCH TECHNIQUES, 4, 2016, Lisboa, Portugal. Anais Eletrônicos... Lisboa: ACM, 2016b. Disponível em: <https://dl.acm.org/citation.cfm?id=3051488.3051516>. Acesso em: 21 jun. 2019.

CANO, S. et al. Principios de Diseño de Juegos Serios para la Enseñanza de Lectoescritura para Niños con Discapacidad Auditiva. In: CONGRESO INTERNACIONAL DE INTERACCIÓN PERSONA-ORDENADOR, 17, 2016, Salamanca, Espanha. Anais Eletrônicos... Salamanca: Ediciones Universidad de Salamanca, 2016c. p. 51-58. Disponível em:

$<$ https://www.researchgate.net/profile/Francisco_Garcia-

Penalvo/publication/308063240_Actas_del_XVII_Congreso_Internacional_de_Interacci on_Persona-Ordenador_-

Interaccion_2016/links/57d8885b08ae601b39afad1b.pdf\#page=51 >. Acesso em: 18 jun. 2019.

CANO, S. et al. Applying the information search process model to analyze aspects in the design of serious games for children with hearing impairment. Universal Access in the Information Society, v. 17, n. 1, p. 83-95, mar. 2018a. Disponível em: $<$ https://link.springer.com/article/10.1007/s10209-016-0520-x>. Acesso em: 29 jun. 2019.

CANO, S. et al. Designing collaborative strategies supporting literacy skills in children with cochlear implants using serious games. In: WORLD CONFERENCE ON INFORMATION SYSTEMS AND TECHNOLOGIES, 6, 2018, Nápoles, Itália. Anais Eletrônicos... Nápoles: AISC, 2018b. Disponível em: <https://link.springer.com/chapter/10.1007/978-3-319-77712-2_126>. Acesso em: 30 jun. 2019.

CANTERI, Rafael dos Passos. Diretrizes para o design de aplicações de jogos eletrônicos para educação infantil de surdos. 79f. Dissertação (Mestrado) Universidade Federal do Paraná. Programa de Pós-Graduação em Informática, Setor de Ciências Exatas. Curitiba, Paraná, Brasil, 2014. Disponível em: <https://acervodigital.ufpr.br/handle/1884/35755>. Acesso em: 21 jun. 2019. 
CAPORUSSO, Nicholas; MKRTCHYA, Lusine; BADIA, Leonardo. A multimodal interface device for online board games designed for sight-impaired people. IEEE Transactions on Information Technology in Biomedicine, v. 14, n. 2, p. 248-254, out. 2009. Disponível em: <https://ieeexplore.ieee.org/abstract/document/5291730>. Acesso em: 2 jul. 2019.

CHEIRAN, Jean Felipe. Jogos inclusivos: diretrizes de acessibilidade para jogos digitais. 162f. Dissertação (Mestrado) - Universidade Federal do Rio Grande do Sul. Programa de Pós-graduação em Computação. Porto Alegre, Rio Grande do Sul, Brasil, 2013. Disponível em: $<$ https://www.lume.ufrgs.br/bitstream/handle/10183/77230/000894957.pdf?sequence=1 \&isAllowed=y>. Acesso em: 10 jun. 2019.

CONRADO, Dália; NUNES-NETO, Nei. Questões sociocientíficas: Fundamentos, propostas de ensino e perspectivas para ações sociopolíticas. Salvador: EDUFBA, 2018.

CORREDOR, Felipe Ernesto Parrado; CARDONA, John Edison Muñoz; GALLO, Oscar Alberto Henao. Diseño de videojuegos serios para la salud. Revista académica e institucional de la UCPR, n. 95, p. 10, ago. 2014. Disponível em: $<$ https://dialnet.unirioja.es/servlet/articulo?codigo=5213954>. Acesso em: 15 jun. 2019.

COSTA, Walber Christiano Lima da; SILVEIRA, Marisa Rosâni Abreu da. Desafios da comunicação no ensino de matemática para alunos surdos. Revista BoEM, v. 2, n. 2, p. 72-87, jan./jul. 2014. Disponível em:

<http://www.periodicos.udesc.br/index.php/boem/article/view/4444>. Acesso em: 29 jun. 2019.

DALLAN, Maria Salomé Soares. Signwriting: escrita visual para língua de sinais no processo de sinalização escrita. In: CONGRESSO NACIONAL DE SURDEZ, 2, 2009, São José dos Campos (SP), Brasil. Anais Eletrônicos... São José dos Campos: CONS, 2009. Disponível em:

$<$ https://www.academia.edu/2445859/SIGNWRITING_ESCRITA_VISUAL_PARA_LIN GUA_DE_SINAIS_\%C5\%93_O_PROCESSO_DE_SINALIZA\%C3\%87\%C3\%800_ES CRITA1>. Acesso em: 9 jul. 2019.

DARSIE, Marta Maria Pontin. Perspectivas Epistemológicas e suas Implicações no Processo de Ensino e de Aprendizagem. Uniciências, v. 3, n. 1, 2015. Disponível em: <http://revista.pgsskroton.com.br/index.php/uniciencias/article/view/1396/1336>. Acesso em: 12 jul. 2019.

DENZIN, Norman; LINCOLN, Yvonna Sessions. O planejamento da pesquisa qualitativa: teorias e abordagens. Porto Alegre: Artmed, 2006.

DESSBESEL, Renata da Silva; SILVA, Sani de Carvalho Rutz da; SHIMAZAKI, Elsa Midori. O processo de ensino e aprendizagem de Matemática para alunos surdos: uma revisão sistemática. Ciência \& Educação (Bauru), v. 24, n. 2, p. 481-500, abr./jun. 2018. Disponível em: <https://www.redalyc.org/service/redalyc/downloadPdf/2510/251055874014/8>. Acesso em: 30 jun. 2019.

FERREIRA, Maria Inês de Jesus. Tecnologia assistiva para crianças com paralisia cerebral sem oralidade: avaliação da comunicação durante atividades com jogos digitais. 81f. Dissertação (Mestrado) - Faculdade Tecnologia SENAI/CIMATEC. Pós- 
Graduação em Modelagem Computacional e Tecnologia Industrial. Salvador, Bahia, Brasil, 2011. Disponível em: <http://repositoriosenaiba.fieb.org.br/handle/fieb/721>. Acesso em: 16 jun. 2019.

FERREIRA, Wendel Menezes; NASCIMENTO, Sandra Patrícia de Faria do. Utilização do jogo de tabuleiro ludo no processo de avaliação da aprendizagem de alunos surdos. Química Nova na Escola, v. 36, n. 1, p. 28-36, fev. 2014. Disponível em: <http://qnesc.sbq.org.br/online/qnesc36_1/06-RSA-26-12.pdf>. Acesso em: 11 jul. 2019.

FIALHO, Neusa Nogueira. Os jogos pedagógicos como ferramentas de ensino. In: CONGRESSO NACIONAL DE EDUCAÇÃO, 8, 2008, Curitiba, Brasil. Anais Eletrônicos... Curitiba: Pontifícia Universidade Católica do Paraná. Disponível em: <http://quimimoreira.net/Jogos\%20Pedagogicos.pdf>. Acesso em: 29 jun. 2019.

FLICK, Uwe. Introdução à pesquisa qualitativa. 3 ed. Porto Alegre: Artmed, 2009.

FORMOSO, Carla Vázquez; RODRÍGUEZ, María Montserrat Castro; RODRÍGUEZ, Jesús Rodríguez. Una taxonomía de materiales didácticos para la inclusión de alumnado con diversidad funcional auditiva. Educatio Siglo XXI, v. 35, n. 3, p. 129152, nov. 2017. Disponível em: <https://revistas.um.es/educatio/article/view/308941>. Acesso em: 27 jun. 2019.

FORTE, Cleberson Eugenio; DAINESE, Carlos Alberto; KIRNER, Cláudio. Universalização da Interface de Jogo Pedagógico para Deficientes Auditivos, Visuais e Não Deficientes através do uso da Realidade Aumentada. In: WORKSHOP DE REALIDADE AUMENTADA, 3, 2006, Rio de Janeiro (RJ), Brasil. Anais Eletrônicos... Rio de Janeiro: LAMCE, 2006. Disponível em: <http://www.lbd.dcc.ufmg.br/colecoes/wra/2006/0015.pdf>. Acesso em: 9 jun. 2019.

GALVÃO, Taís Freire; PEREIRA, Mauricio Gomes. Revisões sistemáticas da literatura: passos para sua elaboração. Epidemiologia e Serviços de Saúde, v. 23, p. 183-184, jan./mar. 2014. Disponível em: <http://www.scielo.br/pdf/ress/v23n1/2237-9622-ress23-01-00183.pdf>. Acesso em: 25 jun. 2019.

GERLING, K. et al. Game design for older adults: effects of age-related changes on structural elements of digital games. In: INTERNATIONAL CONFERENCE ON ENTERTAINMENT COMPUTING, 11, 2012, Bremen, Alemanha. Anais Eletrônicos... Bremen: Springer, 2012. Disponível em:

<https://link.springer.com/chapter/10.1007/978-3-642-33542-6_20>. Acesso em: 7 jul. 2019.

GILLAM, Ronald. A Variety Of Approaches Help Children Overcome Auditory Processing And Language Problems. ScienceDaily, jan. 2008. Disponível em: <www.sciencedaily.com/releases/2008/01/080130150529.htm>. Acesso: 7 jul. 2019.

GIORDANI, Liliane Ferrari; RIBAS, Renato Perez. Jogos de Raciocínio Lógico na Escolarização de Surdos: promovendo movimentos no currículo. In: CONGRESSO INTERNACIONAL DE EDUCAÇÃO, 8, 2013, Gramado (RS), Brasil. Anais Eletrônicos... Gramado: FAURGS. Disponível em: $<\mathrm{http}: / /$ www.inf.ufrgs.br/lobogames/wpcontent/uploads/2015/07/pesquisa_artigo_2013_10.pdf>. Acesso em: 19 jun. 2019. 
GOFFI, Lucyanne Cecília Dias. Jogos, brinquedos e brincadeiras: um estudo sobre a interação de alunos do ensino regular e os que frequentam sala de recursos. $134 \mathrm{f}$. Dissertação (Mestrado) Pós-Graduação em Educação, Universidade Estadual de Maringá, Maringá, Brasil, 2009. Disponível em: <http://alb.com.br/arquivomorto/edicoes_anteriores/anais17/txtcompletos/sem03/COLE_2107.pdf>. Acesso em: 21 jun. 2019.

GONZÁLEZ-PEÑA, P. et al. Uso de las nuevas tecnologías por parte de los psicólogos españoles y sus necesidades. Clínica y salud, v. 28, n. 2, p. 81-91, jul. 2017. Disponível em: <http://scielo.isciii.es/scielo.php?script=sci_arttext\&pid=S1130$52742017000200081>$. Acesso em: 05 jul. 2019.

GRAMMENOS, Dimitris; SAVIDIS, Anthony; STEPHANIDIS, Constantine. UA-Chess: A universally accessible board game. In: INTERNATIONAL CONFERENCE ON HUMAN-COMPUTER INTERACTION, 11, 2005, Las Vegas, Nevada, USA. Anais Eletrônicos... Las Vegas: HCI International, 2015. Disponível em: <https://www.researchgate.net/profile/Anthony_Savidis/publication/241660921_UAChess_A_Universally_Accessible_Board_Game/links/53e4bdf30cf25d674e94e4ce/UAChess-A-Universally-Accessible-Board-Game.pdf >. Acesso em: 20 jun. 2019.

GUIMARÃES et al. Sign Language for all: a framework to inform the design of games to teach Deaf children and their non-Deaf mothers. International Journal of

Education and Research. v. 5; n. 12, dez. 2017. Disponível em: $<$ https://www.ijern.com/journal/2017/December-2017/11.pdf>. Acesso em: 30 jun. 2019.

HUIZINGA, Johan. Homo Ludens. São Paulo: Perspectiva, 2000.

LEUNG, Grace; LAM, Linda. Leisure activities and cognitive impairment in late life: a selective literature review of longitudinal cohort studies. Hong Kong Journal of Psychiatry, v. 17, n. 3, p. 91-101, jul. 2007. Disponível em: $<$ https://go.galegroup.com/ps/anonymous?id=GALE\%7CA172525508\&sid=googleScho lar\&v=2.1\&it=r\&linkaccess $=a b s \& i s s n=10262121 \& p=H R C A \& s w=w>$. Acesso em: 21 jun. 2019.

LEVY, Pierre. Cibercultura. São Paulo: Editora 34, 2010.

LIMA, Gustavo Meireles de Castro; SILVA, Marcelo Didier Fecarotta Alves da. Projeto de desenvolvimento de material didático em educação a distância segundo experiência do usuário. In: CONGRESSO INTERNACIONAL ABED DE EDUCAÇÃO À DISTÂNCIA (CIAED), 23, 2017, Paraná, Foz do Iguaçu, Brasil. Anais Eletrônicos... Foz do Iguaçu: ABED, 2017. Disponível em:

<http://www.abed.org.br/congresso2017/trabalhos/pdf/223.pdf >. Acesso em: 23 jun. 2019.

MARIANI, B. et al. O trabalho fonoaudiológico em uma clínica dialógica bilíngue: estudo de caso. CoDAS, v. 28, n. 5, p. 653-660, set./out. 2016. Disponível em: $<$ http://www.scielo.br/pdf/codas/2016nahead/2317-1782-codas-2317178220162015287.pdf>. Acesso em: 7 jul. 2019.

MASCIO, T. et al. Designing games for deaf children: first guidelines. International Journal of Technology Enhanced Learning, v. 5, n. 3/4, p. 223-239, feb. 2013. Disponível em:

<https://www.researchgate.net/profile/Rosella_Gennari/publication/262277190_Designi 
ng_games_for_deaf_children_First_guidelines/links/54abd00b0cf2bce6aa1dbb0b.pdf >. Acesso em: 21 jun. 2019.

MELONIO, Alessandra; GENNARI, Rosella. How to design games for deaf children: Evidence-based guidelines. In: INTERNATIONAL WORKSHOP ON EVIDENCEBASED TECHNOLOGY ENHANCED LEARNING, 2, 2013, Springer, Heidelberg.

Anais Eletrônicos... Heidelberg: Springer International Publishing Switzerland, 2013. Disponível em: <https://link.springer.com/chapter/10.1007/978-3-319-00554-6_11>. Acesso em: 19 jun. 2019.

MOURA, G. et al. Luz, câmera, libras!: How a mobile game can improve the learning of sign languages. In: INTERNATIONAL CONFERENCE OF DESIGN, USER EXPERIENCE AND USABILITY, 2, 2013, Berlim, Alemanha. Anais Eletrônicos... Berlim: Springer, 2013. Disponível em: <https://link.springer.com/chapter/10.1007/9783-642-39241-2_30>. Acesso: 21 jun. 2019.

NASCIMENTO, Lilian Cristine Ribeiro; LIZ, Ana Paula Cortina. Jogos Digitais no Ensino da Língua Portuguesa para Crianças Surdas. Periferia, v. 9, n. 1, p. 263-289, jan./jun. 2017. Disponível em: <https://www.e-

publicacoes.uerj.br/index.php/periferia/article/view/28763>. Acesso em: 21 jun. 2019.

OLIVEIRA, Marli Dos Santos de; REIS, Maria das Graças Fernandes de Amorim dos. $(R e)$ pensando a função social da escola na atualidade. Série-Estudos-Periódico do Programa de Pós-Graduação em Educação da UCDB, v. 22, n. 44, p. 89-106, jan./abr. 2017. Disponível em: <http://www.serie-estudos.ucdb.br/index.php/serieestudos/article/view/893>. Acesso em: 25 jul. 2019.

OLIVEIRA, S. et al. Construção de jogos e pedagogia visual: mediação da aquisição da libras como língua materna por crianças surdas. In: CONGRESSO INTERNACIONAL DE EDUCAÇÃO INCLUSIVA, 3, 2018, Campina Grande (PB), Brasil. Anais Eletrônicos... Campina Grande: CINTEDI, 2018. Disponível em: $<$ http://www.editorarealize.com.br/revistas/cintedi/resumo.php?idtrabalho=132>. Acesso em: 11 jul. 2019.

OLIVEIRA, S. et al. Jogos analógicos contextualizados à cultura surda-mediando a aquisição da libras como primeira língua por crianças surdas. Brazilian Journal of Development, v. 5, n. 7, p. 8674-8685, jul. 2019. Disponível em: <http://brjd.com.br/index.php/BRJD/article/view/2286>. Acesso em: 30 jul. 2019.

PANTOJA, Ailton da Silva; PEREIRA, Luandierison Marques. Gamificação: como jogos e tecnologias podem ajudar no ensino de idiomas. Estação Científica (UNIFAP), v. 8, n. 1, p. 111-120, jan./abr. 2018. Disponível em: <https://periodicos.unifap.br/index.php/estacao/article/view/2423>. Acesso em: 23 jun. 2019.

PERLIN, Gladis; STROBEL, Karin. Fundamentos da educação de surdos. Florianópolis: UFSC, 2008.

PETRY, Luís Carlos. O Conceito Ontológico de Jogos. In: ALVES, Lynn; COUTINHO, Isa (Org.) Jogos Digitais e Aprendizagem: fundamentos para uma prática baseada em evidências. Campinas: Papirus, 2016, p. 17-42.

PIVETTA, Elisa Maria; SAITO, Daniela Satomi; ULBRICHT, Vânia Ribas. Surdos e acessibilidade: análise de um ambiente virtual de ensino e aprendizagem. Revista 
Brasileira de educação especial, v. 20, n. 1, p. 147-162, jan./mar. 2014. Disponível em: <http://www.scielo.br/scielo.php?pid=S1413-

65382014000100011\&script=sci_abstract\&tlng=pt>. Acesso em: 6 jul. 2019.

PONSA, Pere; GUASCH, Daniel. A human-computer interaction approach for healthcare. Univ Access Inf Soc, v. 17, n. 1, p. 1-3, mar. 2018. Disponível em: <https://link.springer.com/article/10.1007/s10209-016-0515-7\#citeas>. Acesso em: 26 jun. 2019.

QUADROS, Ronice Müller de. Situando as diferenças implicadas na educação de surdos: inclusão/exclusão. Ponto de vista: revista de educação e processos inclusivos, n. 5, p. 81-111, ago. 2003. Disponível em:

<https://periodicos.ufsc.br/index.php/pontodevista/article/viewFile/1246/3850>. Acesso em: 29 jun. 2019.

QUEIROZ, Danilo; CANUTO, Kleber; ONOFRE, Eduardo. Manual de xadrez em libras/português para surdos: o xadrez como ferramenta de letramento bilingue. In: Congresso Nacional de Educação, 4, 2017, João Pessoa (PB), Brasil. Anais Eletrônicos... João Pessoa: CONEDU, 2017. Disponível em: <https://www.editorarealize.com.br/revistas/conedu/trabalhos/TRABALHO_EV073_MD 1_SA10_ID6529_10092017224059.pdf>. Acesso em: 11 jun. 2019.

RAMOS, Daniela Karine; MELO, Hiago Murilo de; MATTAR, João. Jogos digitais na escola e inclusão digital: intervenções para o aprimoramento da atenção e das condições de aprendizagem. Revista Diálogo Educacional, v. 18, n. 58, jul./set. 2018. Disponível em:

<https://periodicos.pucpr.br/index.php/dialogoeducacional/article/view/24120/22985> Acesso em: 23 jun. 2019.

REICHERT, J. et al. Suíte Cauê: Jogos para o Letramento de Crianças Surdas. In: SIMPÓSIO BRASILEIRO DE JOGOS E ENTRETENIMENTO DIGITAL, 14, 2015, Teresina (PI), Brasil. Anais Eletrônicos... Teresina: SBGames, 2015. Disponível em: $<$ https://www.researchgate.net/publication/286879044_Suite_Caue_Jogos_para_o_Let ramento_de_Criancas_Surdas >. Acesso em: 25 jun. 2019.

RIBEIRO, R. et al. Teorias de aprendizagem em jogos digitais educacionais: um panorama brasileiro. RENOTE, v. 13, n. 1, jul. 2015. Disponível em: <https://www.seer.ufrgs.br/renote/article/view/57589>. Acesso: 10 jun. 2019.

RODRIGUES, Carlos Henrique. A Sala de Aula de Surdos Como Espaço Inclusivo: pensando o outro da educação atual. In: ALMEIDA, Wolney Gomes (Org.). Educação de surdos: formação, estratégica e prática docente. Ilhéus (Bahia): SciELO Books, 2017. p. 113-136.

RODRIGUES, Leude Pereira; MOURA, Lucilene Silva; TESTA, Edimárcio. O tradicional e o moderno quanto à didática no ensino superior. Revista Científica do ITPAC, v. 4, n. 3, p. 1-9, jul. 2011. Disponível em: <https://assets.itpac.br/arquivos/Revista/43/5.pdf>. Acesso em: 15 jul. 2019.

RODRIGUES, Patrícia Rocha; ALVES, Lynn Rosalina Gama. Criar e compartilhar games: novas possibilidades de letramento digital para crianças surdas. Revista Novas Tecnologias na Educação, v. 12, n. 2, dez. 2014. Disponível em: <http://repositoriosenaiba.fieb.org.br/handle/fieb/657>. Acesso em: 11 jul. 2019. 
RODRÍGUEZ, V. et al. De la incomunicación sensorial a la bienvenida al mundo: tratamiento con terapia de juego en un niño con sordera. Revista de Psiquiatría Infanto-Juvenil, v. 32, n. 4, p. 209-215, dez. 2015. Disponível em: <http://www.aepnya.eu/index.php/revistaaepnya/article/view/86>. Acesso em: 4 jun. 2019.

SÁ, Nídia Regina Limeira de. Surdos: Qual Escola?. 22 ed. Manaus: Editora Valer e Edua, 2011.

SALIÉS, Tânia Gastão; STAROSKY, Priscila. How a deaf boy gamed his way to second-language acquisition: Tales of intersubjectivity. Simulation \& Gaming, v. 39, n. 2, p. 209-239, jun. 2008. Disponível em:

<https://journals.sagepub.com/doi/abs/10.1177/1046878107310609>. Acesso em: 6 jul. 2019.

SÁNCHEZ, Yeray Segura. La accesibilidad en los videojuegos para el colectivo con problemas auditivos y visuales. 53f. Dissertação (Mestrado), Máster en Subtitulado y Audiodescrípdón. Universidad de Las Palmas de Gran Canaria, Las Palmas, Espanha, 2006. Disponível em:

<https://accedacris.ulpgc.es/bitstream/10553/4153/2/0536015_00000_0000.pdf>.

Acesso em: 8 jul. 2019.

SANTOS, M. et al. A combinação de jogos de tabuleiro com jogos digitais no processo de aprendizagem. In: SIMPÓSIO BRASILEIRO DE JOGOS E ENTRETENIMENTO DIGITAL, 15, 2016, São Paulo (SP), Brasil. Anais Eletrônicos... São Paulo:

SBGames, 2016. Disponível em:

<http://www.sbgames.org/sbgames2016/downloads/anais/157141.pdf>. Acesso em: 21 jun. 2019.

SAVIDIS, Anthony; GRAMMENOS, Dimitris; STEPHANIDIS, Constantine. Developing inclusive e-learning and e-entertainment to effectively accommodate learning

difficulties. Universal Access in the Information Society, v. 5, n. 4, p. 401-419, abr. 2007. Disponível em: <https://link.springer.com/article/10.1007/s10209-006-0059-3>. Acesso em: 15 jun. 2019.

SCHMIDT, Jaison Dairon Ebertz; MARCHI, Ana Carolina Bertoletti De. Usability evaluation methods for mobile serious games applied to health: a systematic review. Universal Access in the Information Society, v. 16, n. 4, p. 921-928, nov. 2017. Disponível em: <https://link.springer.com/article/10.1007/s10209-016-0511-y>. Acesso em: 9 jun. 2019.

SILVA, Valquíria da Conceição. A Importância do Lúdico para o Ensino Aprendizagem de Alunos Surdos. Revista SOMMA, v. 2, n. 2, p. 47-57, jul./dez. 2016. Disponível em: <http://ojs.ifpi.edu.br/revistas/index.php/somma>. Acesso em: 16 jul. 2019.

TORRES, Velda; ALVES, Lynn Rosalina Gama. Professores e os jogos digitais: um olhar sobre as possibilidades pedagógicas destas mídias. A Cor das Letras, v. 14, n. 1, p. 163-176, fev. 2017. Disponível em:

$<$ https://www.researchgate.net/publication/316727169_PROFESSORES_E_OS_JOG OS_DIGITAIS_UM_OLHAR_SOBRE_AS_POSSIBILIDADES_PEDAGOGICAS_DEST AS_MIDIAS> Acesso em: $1 \overline{1}$ jun. $201 \overline{9}$

VIANA, Flávia Roldan; GOMES, Adriana Limaverde. Discutindo aspectos metodológicos de ensino e aprendizagem no atendimento educacional especializado 
para alunos com surdez. Educação: Teoria e Prática, v. 27, n. 54, p. 56-73, jan./abr. 2017. Disponível em:

<https://www.researchgate.net/publication/316627261_DISCUTINDO_ASPECTOS_M ETODOLOGICOS DE ENSINO_E_APRENDIZAGEM_NO_ATENDIMENTO_EDUCA CIONAL_ESPECIALIZADO_PARA_ALUNOS_COM_SURDEZ>. Acesso em: 8 jul. 2019.

WAKI, Ana; FUJIYOSHI; Guilherme; ALMEIDA, Leonelo. Games accessibility for deaf people: evaluating integrated guidelines. In: INTERNATIONAL CONFERENCE ON UNIVERSAL ACCESS IN HUMAN-COMPUTER INTERACTION, 9, 2015, Los Angeles, CA, USA. Anais Eletrônicos... Los Angeles: Springer Cham, 2015. Disponível em: < https://link.springer.com/chapter/10.1007/978-3-319-20684-4_48>. Acesso em: 10 jun. 2019.

WITKOSKI, Sílvia Andreis. Surdez e preconceito: a norma da fala e o mito da leitura da palavra falada. Revista Brasileira de Educação, v. 14, n. 42, p. 565-575, set./dez. 2009. Disponível em: <http://www.scielo.br/pdf/rbedu/v14n42/v14n42a12.pdf>. Acesso em: 25 jun. 2019.

VASCONCELOS, F. et al. The learning of adolescent students about the disabled person using board game. Open Journal of Nursing, v. 5, n. 03, p. 173, mar. 2015. Disponível em:

<https://www.researchgate.net/profile/Lorita_Pagliuca/publication/273383652_The_Lea rning_of_Adolescent_Students_about_the_Disabled_Person_Using_Board_Game/link s/5694f21b08ae820ff074893f.pdf >. Acesso em: 22 jun. $201 \overline{9}$.

VEGA, Santiago Cano; MORALES, Camilo Andrés Martínez; CHACÓN, María Alejandra Tamayo. Juego para el aprendizaje de la Lengua de Señas Colombiana entre Niños Sordos de 3 años y sus Padres facilitando su comunicación en el hoga. 51f. Trabalho de Conclusão de Curso (TCC) - Facultad de Arquitectura y Diseño. Programa de Diseño Industrial. Bogotá, Colômbia, 2018. Disponível em: <https://repository.javeriana.edu.co/handle/10554/34675>. Acesso em: 26 jun. 2019.

VYGOTSKY, Lev. Aprendizagem e desenvolvimento intelectual na idade escolar. Linguagem, desenvolvimento e aprendizagem, v. 10, p. 103-117, 1988. Disponível em: <http://www.luzimarteixeira.com.br/wpcontent/uploads/2011/03/aprendizagemedesenvolvimentointelectualnaidadeescolar.pdf >. Acesso em: 27 jun. 2019.

YEE, Cristina Suemay Manresa; SANSÓ, Ramón Mas; CANO, Sandra Patricia. Juego serio para entrenar habilidades auditivas en niños con discapacidad auditiva. Revista Colombiana de Computación, v. 19, n. 1, p. 56-68, jan. 2018. Disponível em: $<$ https://dialnet.unirioja.es/servlet/articulo?codigo=6720881>. Acesso em: 20 jul. 2019.

YUAN, Bei; FOLMER, Eelke; HARRIS, Frederick. Game accessibility: a survey. Universal Access in the information Society, v. 10, n. 1, p. 81-100, mar. 2011. Disponível em: <https://link.springer.com/article/10.1007/s10209-010-0189-5>. Acesso em: 16 jul. 2019. 